Supporting Information

\title{
Highly Sensitive, Tunable Chirality Amplification through Space Visualized for Gold Nanorods Capped with Axially Chiral Binaphthyl Derivatives
}

\author{
Ahlam Nemati, ${ }^{\dagger}$ Sasan Shadpour, ${ }^{\dagger}$ Lara Querciagrossa,,${ }^{\pi}$ Taizo Mori, ${ }^{\ddagger}$ Claudio Zannoni, ${ }^{\pi}$ and \\ Torsten Hegmann ${ }^{\dagger \S^{*}}$
}

${ }^{\dagger}$ Advanced Materials and Liquid Crystal Institute, Chemical Physics Interdisciplinary Program, Kent State University, Kent, Ohio 44242, United States

"Dipartimento di Chimica Industriale "Toso Montanari” and INSTM, Università di Bologna, Viale Risorgimento 4, IT-40136 Bologna, Italy

${ }^{\ddagger}$ Graduate School of Frontier Science, The University of Tokyo, 5-1-5, Kashiwanoha, Kashiwa 277-0827, Japan

§Department of Chemistry and Biochemistry, Kent State University, Kent, Ohio 44242, United States. 
SECTION S1: SYNTHESIS \& CHARACTERIZATION OF MATERIALS, SAMPLE PREPARATION

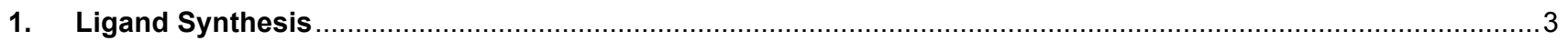

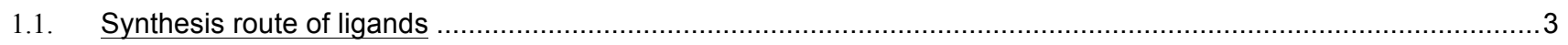

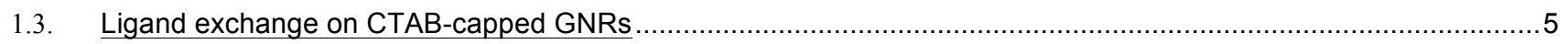

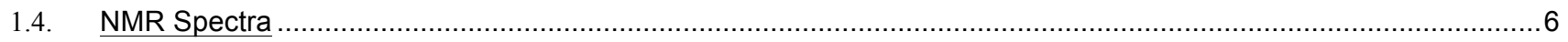

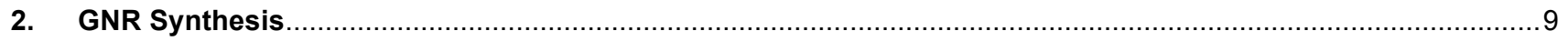

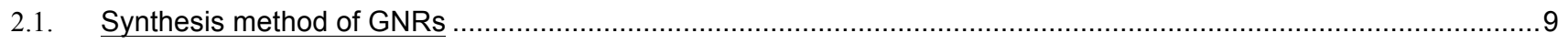

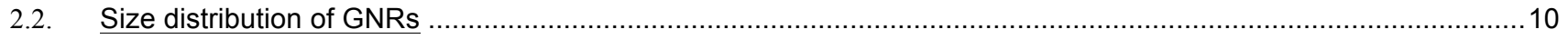

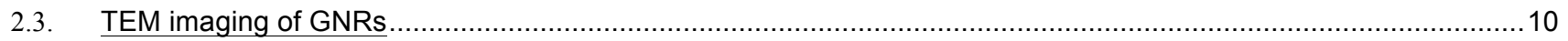

3. Thermogravimetric Analysis (TGA) of binaphthyl-capped GNR: (S)-enantiomers ................................12

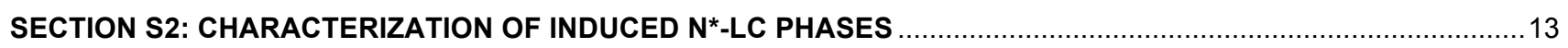

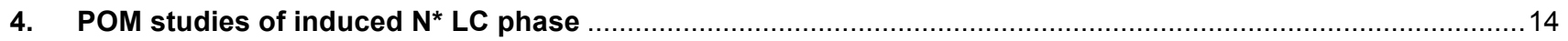

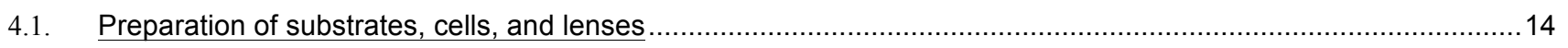

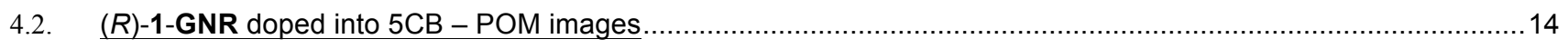

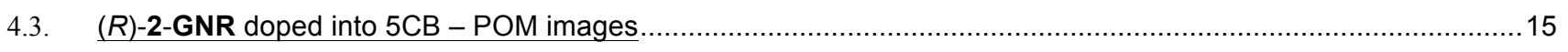

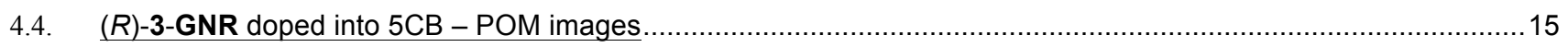

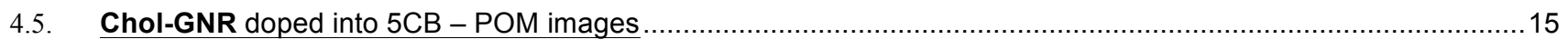

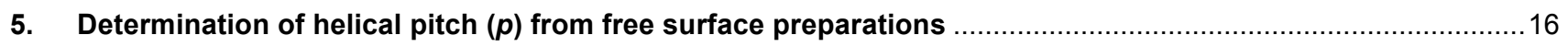

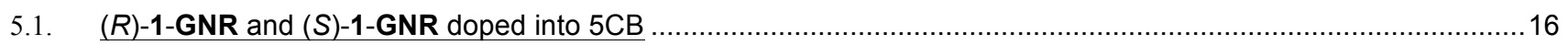

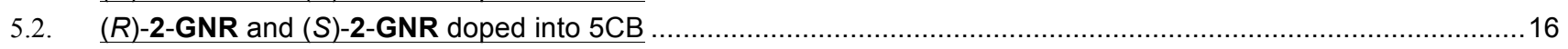

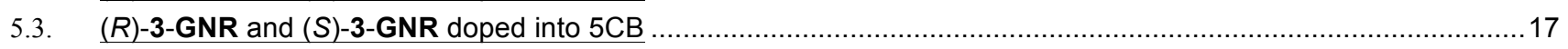

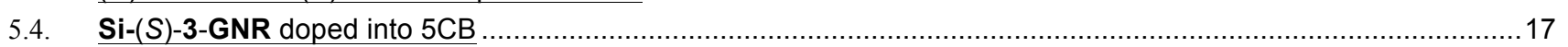

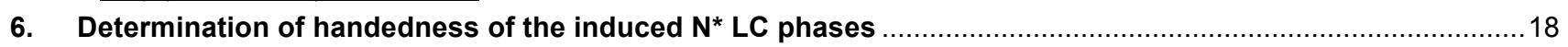

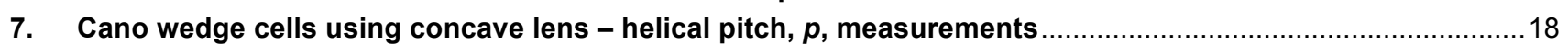

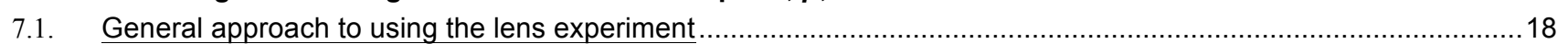

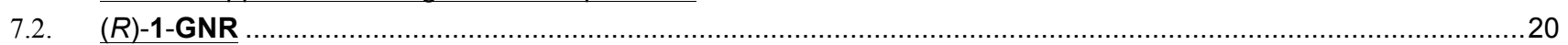

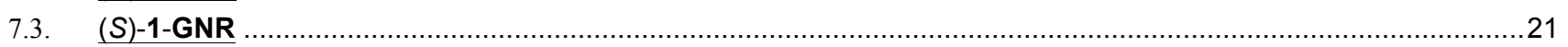

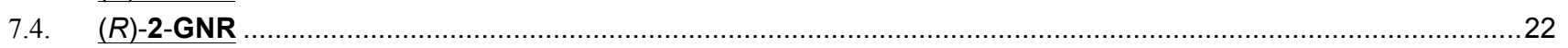

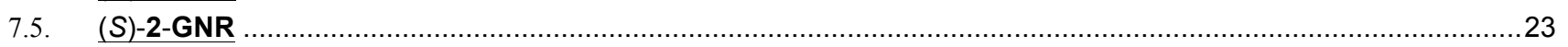

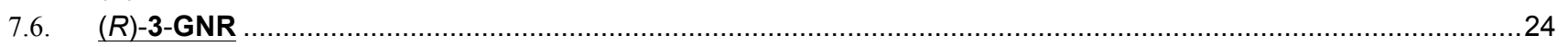

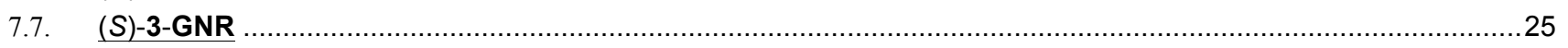

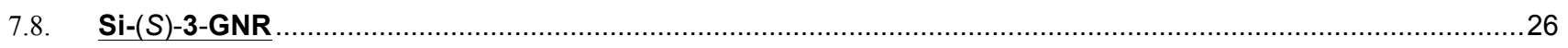

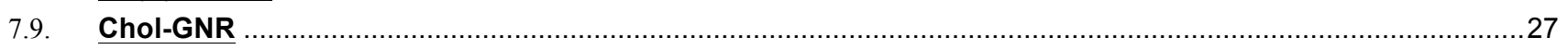

8. Thin film ICD spectra of the induced $N^{*}$-LC phase by doping 5CB with $(R)$-binaphthyl-capped GNRs ...........28

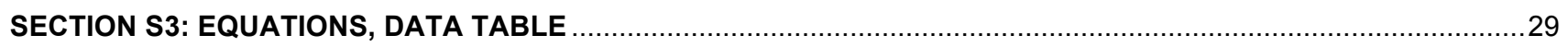

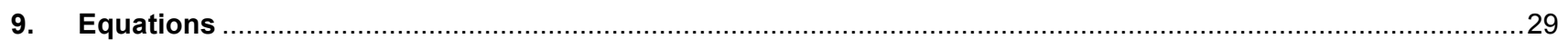

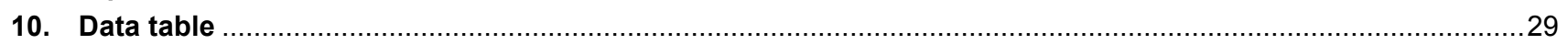

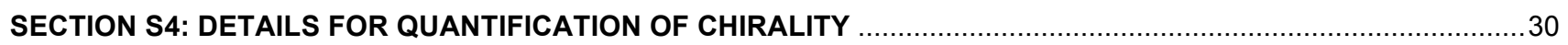

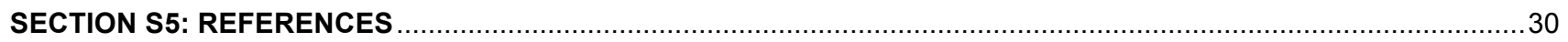




\section{SECTION S1: SYNTHESIS \& CHARACTERIZATION OF MATERIALS, SAMPLE PREPARATION}

\section{Ligand Synthesis}

1.1. Synthesis route of ligands
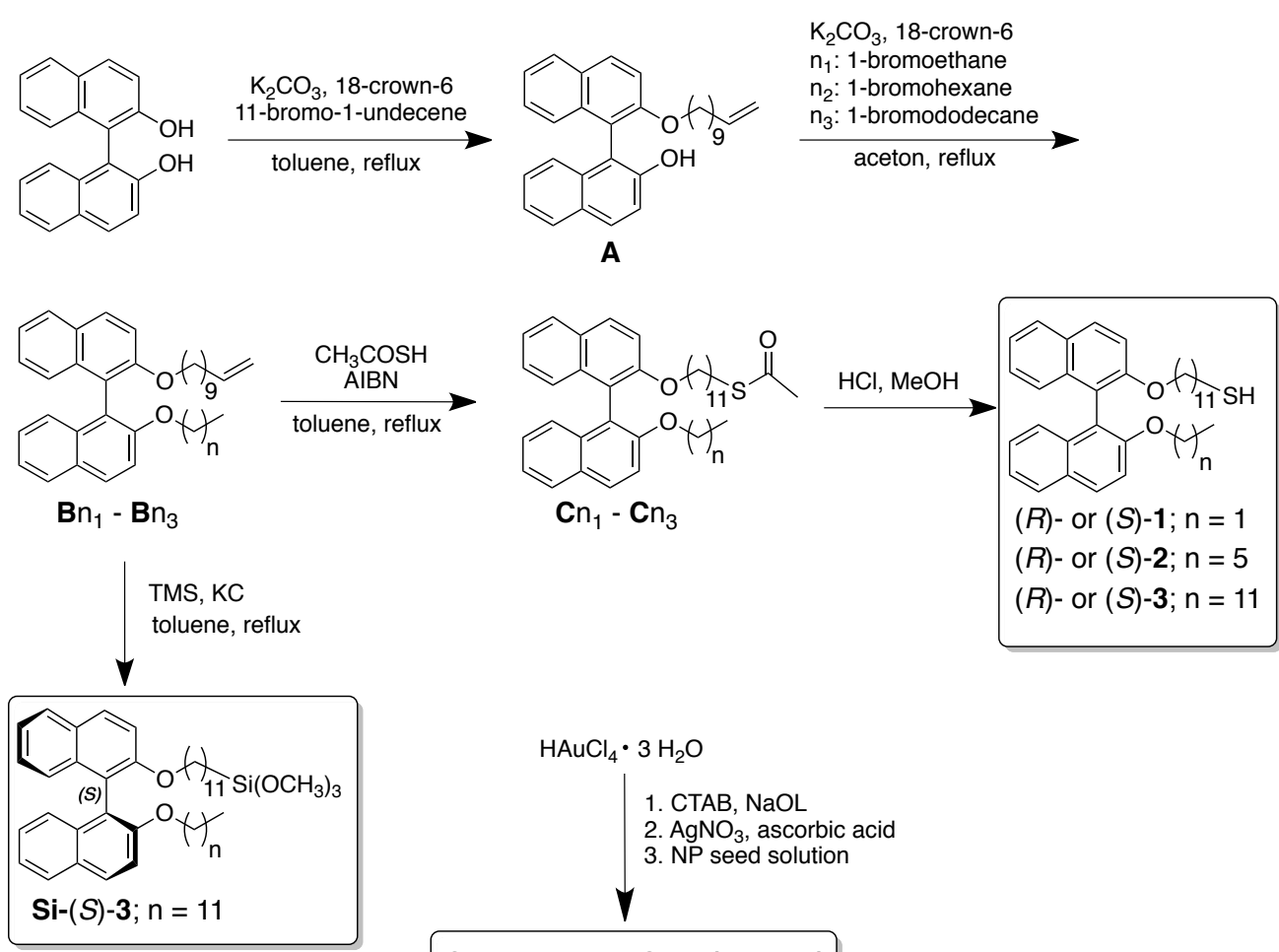

$\mathrm{HAuCl}_{4} \cdot 3 \mathrm{H}_{2} \mathrm{O}$

1. CTAB, $\mathrm{NaO}$

2. $\mathrm{AgNO}_{3}$, ascorbic acid

3. NP seed solution

CTAB-capped GNR (AR: 4.2)

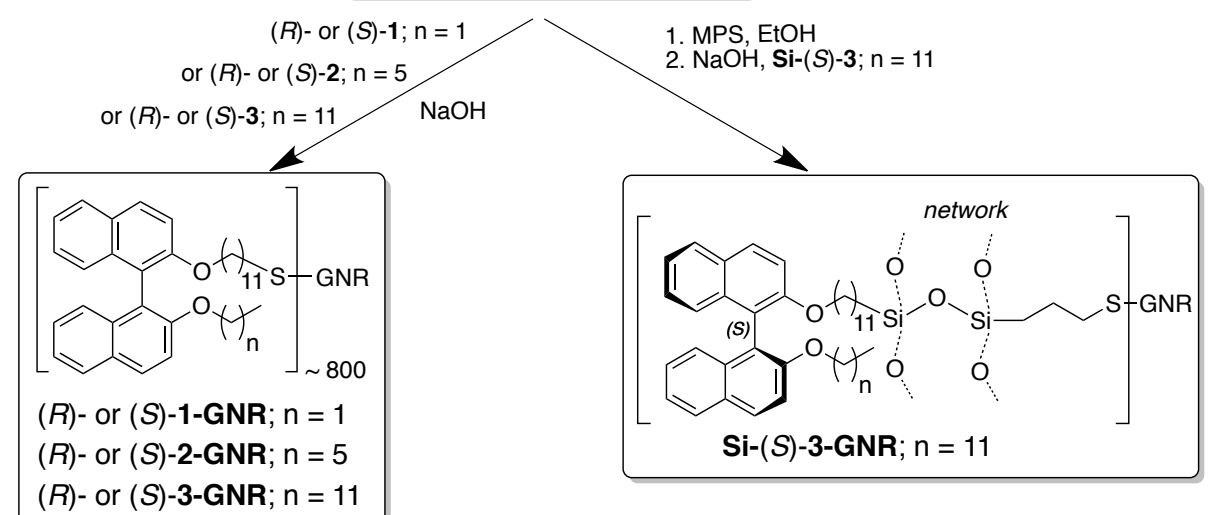

Scheme S1. Synthetic routes for ligand synthesis and GNR functionalization with axially chiral binaphthyl moieties.

\subsection{Ligand synthesis procedure ${ }^{\mathrm{S} 1}$}

For the synthesis of compounds A, B and C: $50 \mathrm{~mL}$ of dry acetone was added into a $100 \mathrm{~mL}$ 3-neck flask containing $(R)$ - or $(S)-(+)-1,1^{\prime}-\mathrm{bi}\left(2-\right.$-naphthol) $(538 \mathrm{mg}, 1.9 \mathrm{mmol})$ and $\mathrm{K}_{2} \mathrm{CO}_{3}(309 \mathrm{mg}, 2.2 \mathrm{mmol}$ ), and a catalytic amount of 18-crown-6. The solution was refluxed at $60{ }^{\circ} \mathrm{C}$ for $1 \mathrm{~h}$, and then 11-bromo-1-undecene (446 $\mathrm{mg} 1.9 \mathrm{mmol}$ ) was added to the solution at $60^{\circ} \mathrm{C}$ for $36 \mathrm{~h}$. All products in each step were purified by silica gel column chromatography (chloroform : $n$-hexane $=1: 1$ ). For the second step, the synthesis followed the procedure described for $\mathbf{A}$ using: $\mathbf{A}$ (620 mg, $2.2 \mathrm{mmol}), \mathrm{K}_{2} \mathrm{CO}_{3}(344 \mathrm{mg}, 2.5 \mathrm{mmol})$, and bromoethane (497 $\mathrm{mg}, 2.2 \mathrm{mmol}$ ) for $\mathrm{Bn}_{1}$; $\mathbf{A}(310 \mathrm{mg}, 1.1 \mathrm{mmol}), \mathrm{K}_{2} \mathrm{CO}_{3}(388 \mathrm{mg}, 1.2 \mathrm{mmol})$, and 1-bromohexane (248 mg, 1.1 
$\mathrm{mmol}$ ) for $\mathrm{Bn}_{2}$; and $\mathbf{A}(434 \mathrm{mg}, 1.5 \mathrm{mmol}), \mathrm{K}_{2} \mathrm{CO}_{3}(240 \mathrm{mg}, 1.7 \mathrm{mmol}$ ), and 1-bromdodecane (348 mg, 1.5 $\mathrm{mmol}$ ) for $\mathbf{B n}_{3}$. For compound $\mathbf{C}$, a catalytic amount of AIBN in toluene was placed in a $50 \mathrm{~mL}$ 3-neck flask. To this reaction mixture as an example for $\mathbf{C n}_{1}: \mathbf{B n}_{1}(199 \mathrm{mg}, 0.43 \mathrm{mmol})$ and thioacetic acid $(270 \mathrm{mg}, 3.5 \mathrm{mmol})$ were added and the mixture was refluxed at $60{ }^{\circ} \mathrm{C}$ for 1 day under $\mathrm{N}_{2}$ flow. The hydrolysis under acidic conditions was performed by $10 \mu \mathrm{L}$ concentrated $(37 \%) \mathrm{HCl}$ in $25 \mathrm{~mL} \mathrm{MeOH}$ giving (S)- and (R)-1, (S)- and $(R)-2$, as well as $(S)$ - and $(R)-3$.

(S)-1 or $(R)$-1: (S)- or (R)-2-[(2'-ethoxy-1,1'-binaphthalen-2-yl)oxy]undecanethiol

${ }^{1} \mathrm{H}$ NMR ( $\left.\mathrm{CDCl}_{3}, 400 \mathrm{MHz}, \delta / \mathrm{ppm}\right): 7.94$ (d, 2H, $J=8.8 \mathrm{~Hz}$, naphthyl), 7.86 (d, 2H, J = 8.1 Hz, naphthyl), 7.42 (d, 2H, J = 9.2 Hz, naphthyl), 7.31 (m, 2H, naphthyl), 7.20 (m, 2H, naphthyl), 7.14 (m, 2H, naphthyl), 4.04, 3.94 (m, 4H, naphthyl-O- $\left.\underline{\mathrm{C}}_{2}-\right), 2.54$ (q, $\left.2 \mathrm{H}, J=7.3 \mathrm{~Hz},-\underline{\mathrm{C}}_{2}-\mathrm{SH}\right), 1.62\left(\mathrm{~m}, 2 \mathrm{H}\right.$, naphthyl-O- $\left.\mathrm{CH}_{2}-\mathrm{C}_{\underline{H}_{2}}\right), 1.40$ (m $2 \mathrm{H}$, $\left.-\mathrm{CH}_{2}-\mathrm{CH}_{2}-\mathrm{SH}\right), 1.38-1.11\left(\mathrm{~m}, 8 \mathrm{H},-\mathrm{CH}_{2}\right), 1.06\left(\mathrm{~m}, 3 \mathrm{H},-\mathrm{CH}_{3}\right), 1.03-0.90\left(\mathrm{~m}, 6 \mathrm{H},-\mathrm{CH}_{2}{ }^{-}\right) .{ }^{13} \mathrm{C} \mathrm{NMR}\left(\mathrm{CDCl}_{3}\right.$, $100 \mathrm{MHz}, \delta / \mathrm{ppm}$ ): 154.6, 154.4 (C-O, naphthyl) 134.2, 129.3, 129.1, 127.9, 127.8, 126.1, 126.0, 123.5, 120.8 (naphthyl), 116.0, 115.9 (C-1,1', naphthyl), 69.8, 65.3 ( $\mathrm{CH}_{2} \mathrm{O}-$ naphthyl), 34.1 (- $\left.\mathrm{CH}_{2}-\mathrm{SH}\right)$ 29.6, 29.5, 29.2, 29.1, 28.5, 25.6, $24.7\left(\mathrm{CH}_{2}\right), 15.1\left(\mathrm{CH}_{3}\right)$.

(S)-2 or $(R)-2$ : $(S)$ - or $(R)-2$ - [(2'-hexoxy-1,1'-binaphthalen-2-yl)oxy] undecanethiol ${ }^{1} \mathrm{H} \mathrm{NMR}\left(\mathrm{CDCl}_{3}, 400 \mathrm{MHz}, \delta / \mathrm{ppm}\right.$ ): 7.93 (d, 2H, $J=9.2 \mathrm{~Hz}$, naphthyl), 7.85 (d, 2H, J = 8.8 Hz, naphthyl), 7.41 (d, $2 \mathrm{H}, J=8.8 \mathrm{~Hz}$, naphthyl), 7.30 (m, 2H, naphthyl), 7.20 (m, 2H, naphthyl), $7.16(\mathrm{~m}, 2 \mathrm{H}$, naphthyl), 3.93 (m, $4 \mathrm{H}$, naphthyl-O- $\left.\mathrm{C}_{2}-{ }^{-}\right), 2.54\left(\mathrm{q}, 2 \mathrm{H}, J=7.6 \mathrm{~Hz},-\underline{\mathrm{C}}_{2}-\mathrm{SH}\right), 1.64\left(\mathrm{~m}, 4 \mathrm{H}\right.$, naphthyl-O- $\left.\mathrm{CH}_{2}-\mathrm{C}_{2}-\underline{H}^{-}\right), 1.41(\mathrm{~m} 4 \mathrm{H}$, $\left.-\mathrm{CH}_{2}-\mathrm{CH}_{2}-\mathrm{SH}\right), 1.39-0.90\left(\mathrm{~m}, 22 \mathrm{H},-\mathrm{CH}_{2}-\right), 0.74\left(\mathrm{t}, 3 \mathrm{H}, \mathrm{J}=7.0 \mathrm{~Hz},-\mathrm{CH}_{3}\right) .{ }^{13} \mathrm{C} \mathrm{NMR}\left(\mathrm{CDCl}_{3}, 100 \mathrm{MHz}, \delta / \mathrm{ppm}\right)$ : 154.5 (C-O, naphthyl) 134.2, 129.2, 129.0, 127.7, 126.0, 125.6, 125.5, 123.4, 120.7 (naphthyl), 115.9 (C-1,1', naphthyl), 69.8 ( $\mathrm{CH}_{2} \mathrm{O}-$ naphthyl), $34.1\left(-\mathrm{CH}_{2}-\mathrm{SH}\right)$ 31.3, 29.5, 29.4, 29.3, 29.2, 29.1, 28.4, 25.6, 24.7, 22.4 $\left(\mathrm{CH}_{2}\right), 13.9\left(\mathrm{CH}_{3}\right)$.

(S)-3 or $(R)$-3: $(S)$ - or $(R)-2-\left[\left(2 '-d o d e c a n o x y-1,1^{\prime}\right.\right.$-binaphthalen-2-yl)oxy]undecanethiol

${ }^{1} \mathrm{H}$ NMR $\left(\mathrm{CDCl}_{3}, 400 \mathrm{MHz}, \delta / \mathrm{ppm}\right): 7.93$ (d, $2 \mathrm{H}, J=8.8 \mathrm{~Hz}$, naphthyl), 7.85 (d, 2H, $J=8.1 \mathrm{~Hz}$, naphthyl), 7.42 (d, $2 \mathrm{H}, J=9.2 \mathrm{~Hz}$, naphthyl), $7.31(\mathrm{~d}, 2 \mathrm{H}, J=8.1 \mathrm{~Hz}$, naphthyl), $7.21(\mathrm{~m}, 2 \mathrm{H}$, naphthyl), $7.18(\mathrm{~m}, 2 \mathrm{H}$, naphthyl), $3.94\left(\mathrm{~m}, 4 \mathrm{H}\right.$, naphthyl-O- $\left.\underline{\mathrm{H}}_{2^{-}}\right), 2.54\left(\mathrm{q}, 2 \mathrm{H}, J=7.6 \mathrm{~Hz},-\mathrm{C}_{2}-\mathrm{SH}\right), 1.65\left(\mathrm{~m}, 4 \mathrm{H}\right.$, naphthyl-O- $\left.\mathrm{CH}_{2^{-}} \mathrm{C}_{2_{2}}\right) 1.63(\mathrm{t}$, $4 \mathrm{H}, J=7.2$, naphthyl-O- $\mathrm{CH}_{2}-\mathrm{CH}_{2}-1.41\left(\mathrm{~m} 4 \mathrm{H},-\underline{\mathrm{CH}}_{2}-\mathrm{CH}_{2}-\mathrm{SH}\right), 1.39-0.95\left(\mathrm{~m}, 34 \mathrm{H},-\mathrm{CH}_{2}-\right), 0.92(\mathrm{t}, 3 \mathrm{H}, J=7.0$ $\left.\mathrm{Hz},-\mathrm{CH}_{3}\right) .{ }^{13} \mathrm{C} \mathrm{NMR}\left(\mathrm{CDCl}_{3}, 100 \mathrm{MHz}, \delta / \mathrm{ppm}\right): 154.6$ (C-O, naphthyl) 134.2, 129.3, 129.0, 127.8, 126.0, 125.5, 123.4, 120.7 (naphthyl), 115.9 (C-1,1', naphthyl), 69.8 ( $\mathrm{CH}_{2} \mathrm{O}$-naphthyl), 34.1 (- $\left.\mathrm{CH}_{2}-\mathrm{SH}\right)$ 31.2, 29.7, 29.6, 29.5, 29.4, 29.3, 29.2, 29.1, 28.6, 28.4, 25.6, 24.7, $22.7\left(\mathrm{CH}_{2}\right), 14.2\left(\mathrm{CH}_{3}\right)$.

To obtain Si-(S)-3, all glassware should be silanized following standard protocols using a $2 \%$ solution (by volume) of chlorotrimethylsilane in toluene. Compound $(S)-\mathrm{Bn}_{3}(393 \mathrm{mg}, 1.54 \mathrm{mmol}$ ) and trimethoxysilane (TMS) $(979 \mu \mathrm{L}, 1.5 \mathrm{mmol})$ were dissolved in dry toluene and the resulting solution was allowed to stir for 30 minutes. Then platinum(0)-1,3-divinyl-1,1,3,3-tetramethyldisiloxane (aka Karstedt's catalyst, KC) in xylene (40 
$\mathrm{mg}, 0.02 \mathrm{mmol}$ ) was added and stirred for $20 \mathrm{~h}$. The excess TMS and solvent were removed under reduced pressure. The residue was dissolved in dichloromethane/ethyl acetate (1:1) and any undissolved part was discarded. The filtrate was collected and recrystallized twice.

(S)-12-((2'-(dodecyloxy)-[1,1'-binaphthalen]-2-yl)oxy)dodecyl)trimethoxysilane, Si-(S)-3:

${ }^{1} \mathrm{H}$ NMR $\left(\mathrm{CDCl}_{3}, 400 \mathrm{MHz}, \delta / \mathrm{ppm}\right): 7.93$ (d, $2 \mathrm{H}, J=8.8 \mathrm{~Hz}$, naphthyl), 7.85 (d, $2 \mathrm{H}, J=8.1 \mathrm{~Hz}$, naphthyl), 7.42 (d, $2 \mathrm{H}, J=9.2 \mathrm{~Hz}$, naphthyl), $7.31(\mathrm{~d}, 2 \mathrm{H}, J=8.1 \mathrm{~Hz}$, naphthyl), $7.21(\mathrm{~m}, 2 \mathrm{H}$, naphthyl), $7.18(\mathrm{~m}, 2 \mathrm{H}$, naphthyl), $3.94\left(\mathrm{~m}, 4 \mathrm{H}\right.$, naphthyl-O- $\left.\left.\mathrm{C}_{2_{2}}-\right), 3.65(\mathrm{~S}, 9 \mathrm{H}),\left(\mathrm{Si}\left(\mathrm{C}_{\mathrm{H}_{3}}\right)_{3}\right), 1.8 \mathrm{H}, J=7.3 \mathrm{~Hz},-\mathrm{C}_{\underline{2}}-\mathrm{SH}\right), 1.65(\mathrm{~m}, 4 \mathrm{H}$, naphthyl-O- $\mathrm{CH}_{2}-\mathrm{C}_{2}-$ ), 1.63 (t, $4 \mathrm{H}, J=7.2$, naphthyl-O- $\mathrm{CH}_{2}-\mathrm{C}_{2}-$ ), $1.41\left(\mathrm{~m}, 4 \mathrm{H},-\mathrm{CH}_{2}-\mathrm{CH}_{2}-\mathrm{SH}\right), 1.39-0.95$ (m, $\left.34 \mathrm{H},-\mathrm{CH}_{2}-\right), 0.92\left(\mathrm{t}, 3 \mathrm{H}, J=7.0 \mathrm{~Hz},-\mathrm{CH}_{3}\right) .{ }^{13} \mathrm{C} \mathrm{NMR}\left(\mathrm{CDCl}_{3}, 100 \mathrm{MHz}, \delta / p p m\right): 154.6$ (C-O, naphthyl) 134.2, 129.3, 129.0, 127.8, 126.0, 125.5, 123.4, 120.7 (naphthyl), 115.9 (C-1,1', naphthyl), 69.8 ( $\mathrm{CH}_{2} \mathrm{O}$-naphthyl), 50.54,( $\left(\mathrm{Si}\left(\mathrm{CH}_{3}\right)_{3}\right), 34.1\left(-\mathrm{CH}_{2}-\mathrm{SH}\right)$ 31.2, 29.7, 29.6, 29.5, 29.4, 29.3, 29.2, 29.1, 28.6, 28.4, 25.6, 24.7, 22.7 $\left(\mathrm{CH}_{2}\right), 14.2\left(\mathrm{CH}_{3}\right)$.

The synthesis and complete spectroscopic characterization of the cholesterol-disulfide (structure shown below) used in the preparation of the Chol-GNRs was described already elsewhere. ${ }^{\text {s2 }}$

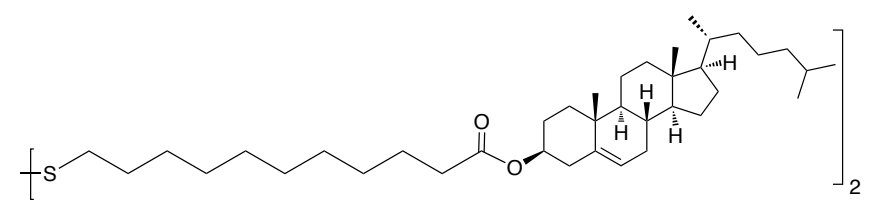

\subsection{Ligand exchange on CTAB-capped GNRs}

The ligand exchange from CTAB to the six ligands with three different aliphatic chain lengths $((R)-1,(R)-2$, and $(R)-3$ as well as $(S)-\mathbf{1},(S)-2$, and $(S)-3$ ) followed the same method as published previously. After removing any excess of CTAB by washing with a $1: 1$ ratio of chloroform/DI water, $4 \mathrm{~mL}$ of the CTAB-GNR solution in a $10 \mathrm{~mL}$ glass vial and $4 \mathrm{~mL}(1: 1=v / v)$ of $(R)-\mathbf{1},(R)-\mathbf{2},(R)-\mathbf{3},(S)-\mathbf{1},(S)-\mathbf{2}$, or $(S)-3$ were dissolved in chloroform and mixed. Then, adjustment of the $\mathrm{pH}$ to basic conditions $(\mathrm{pH} \sim 10)$ using a few drops of aqueous $1 \mathrm{M} \mathrm{NaOH}$ solution provided GNRs functionalized by the binaphthyl thiolates after stirring for $6 \mathrm{~h}$ to yield $(R)-1-G N R$, $(R)-2-G N R$, and (R)-3-GNR as well as (S)-1-GNR, (S)-2-GNR, and (S)-3-GNR.

For the exchange of CTAB with $\mathbf{S i - ( S ) - 3 , ~ C T A B ~ i s ~ f i r s t ~ r e p l a c e d ~ b y ~ ( 3 - m e r c a p t o p r o p y l ) t r i m e t h o x y s i l a n e ~ ( M P S ) ~}$ followed by addition of the binaphthyl-silane $\mathbf{S i}-(S)-3$ and adjustment of the $\mathrm{pH}$ to slightly basic conditions $(\mathrm{pH}=$ 10) using a few drops of aqueous $1 \mathrm{M} \mathrm{NaOH}$ solution to yield $\mathbf{S i - ( S ) - 3 - G N R s . ~}$ 


\section{4. $\quad$ NMR Spectra}

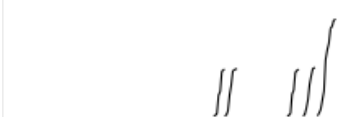

$\iint$
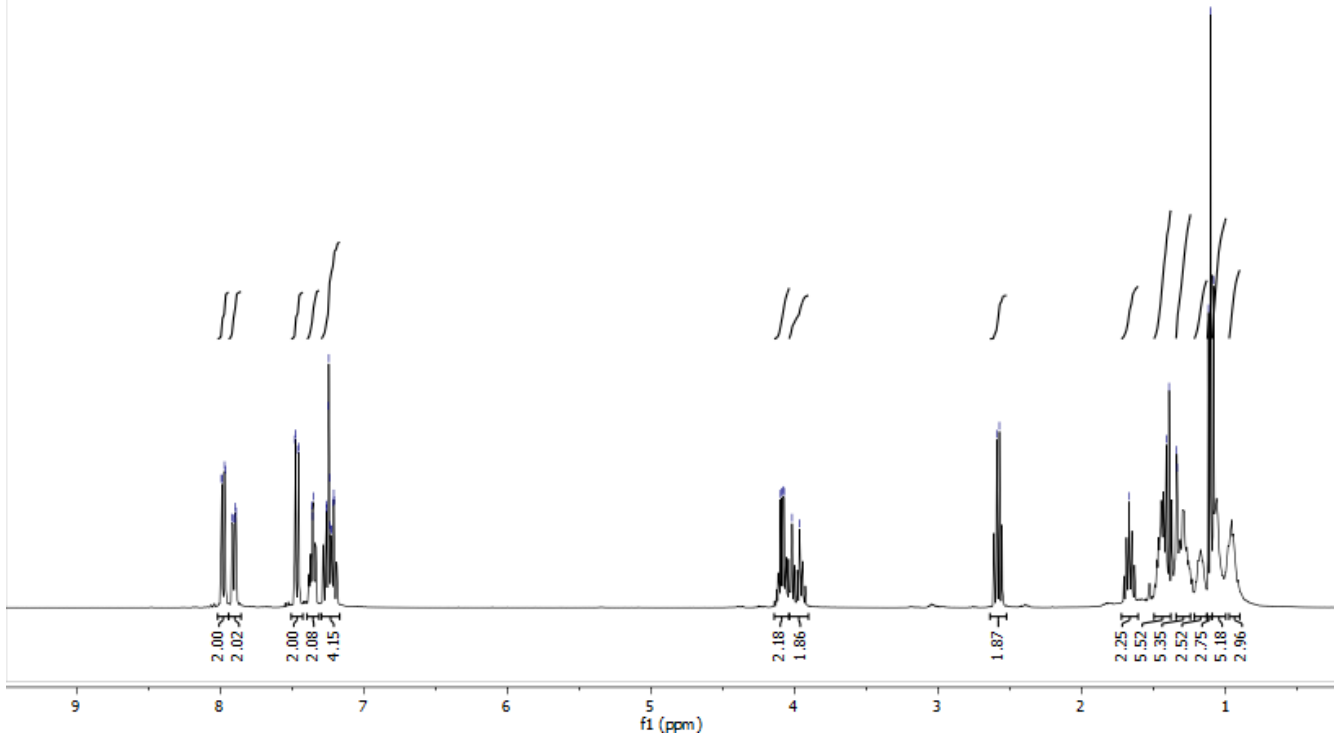

Figure S1. $\quad{ }^{1} \mathrm{H}$ NMR spectrum of $(R)-1((S)-1$ is identical).
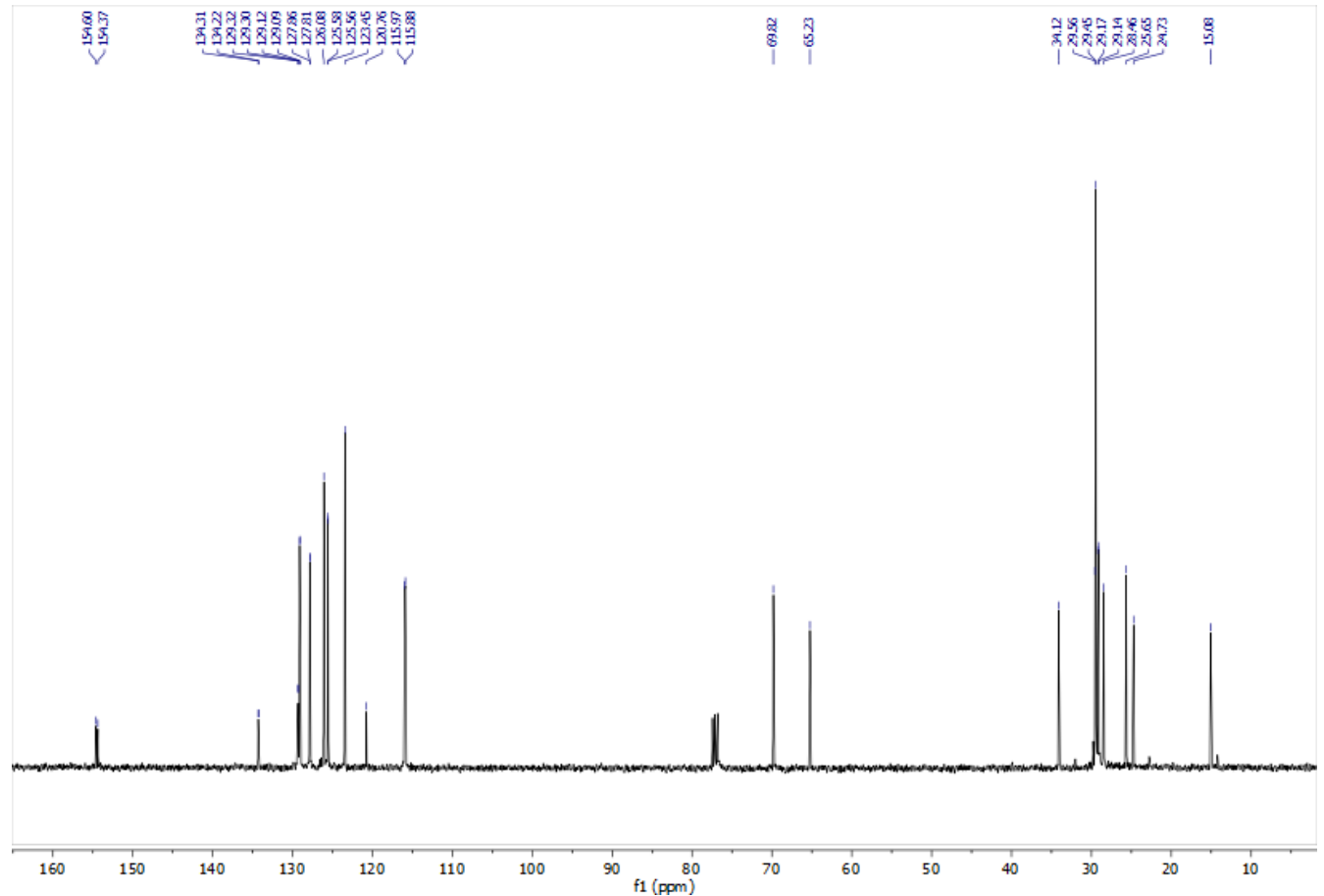

Figure S2. ${ }^{13} \mathrm{C}$ NMR spectrum of $(R)-\mathbf{1}((S)-\mathbf{1}$ is identical). 


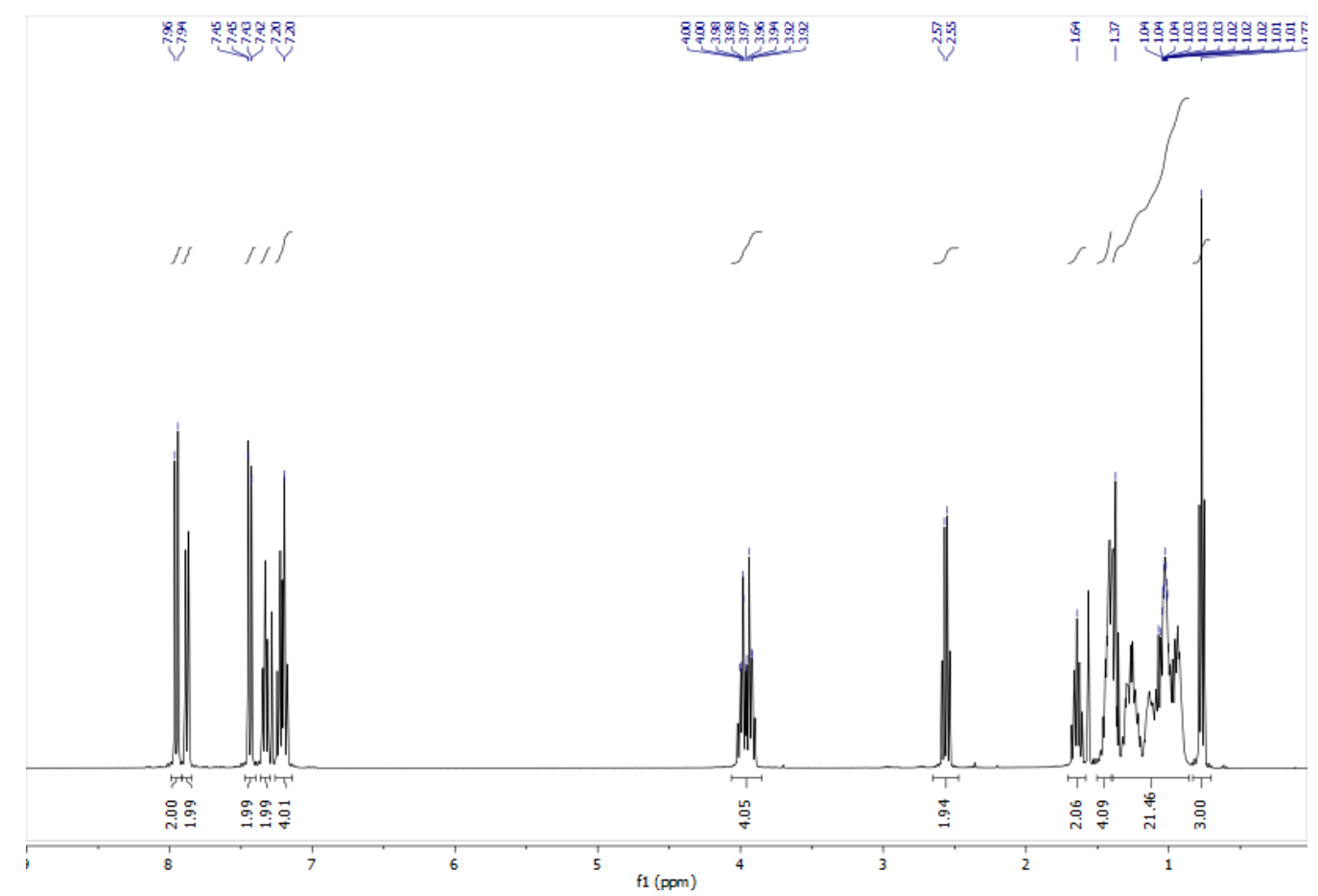

Figure S3. $\quad{ }^{1} \mathrm{H}$ NMR spectrum of $(R)-2((S)-2$ is identical).

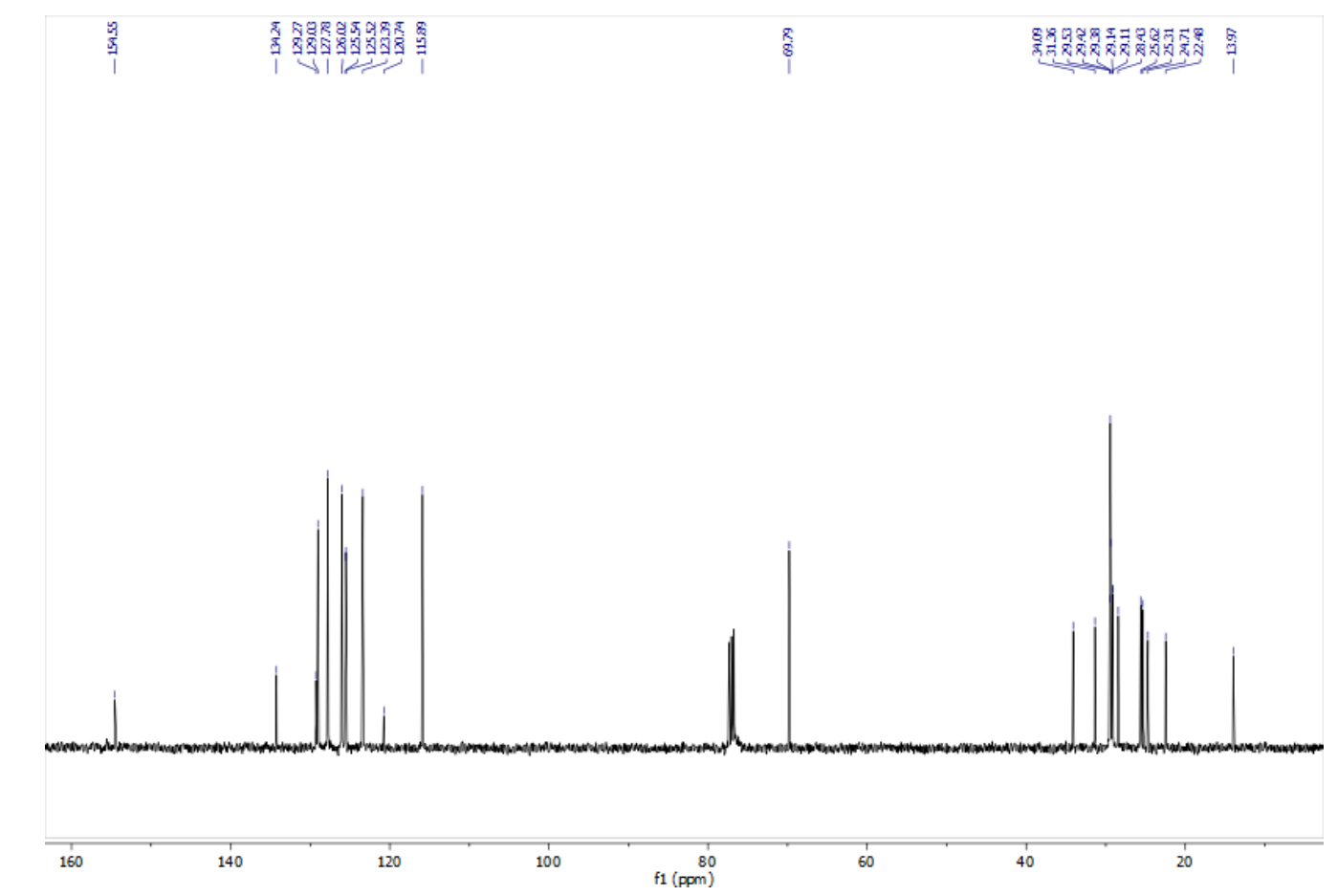

Figure S4. $\quad{ }^{13} \mathrm{C}$ NMR spectrum of $(R)-2((S)-2$ is identical). 


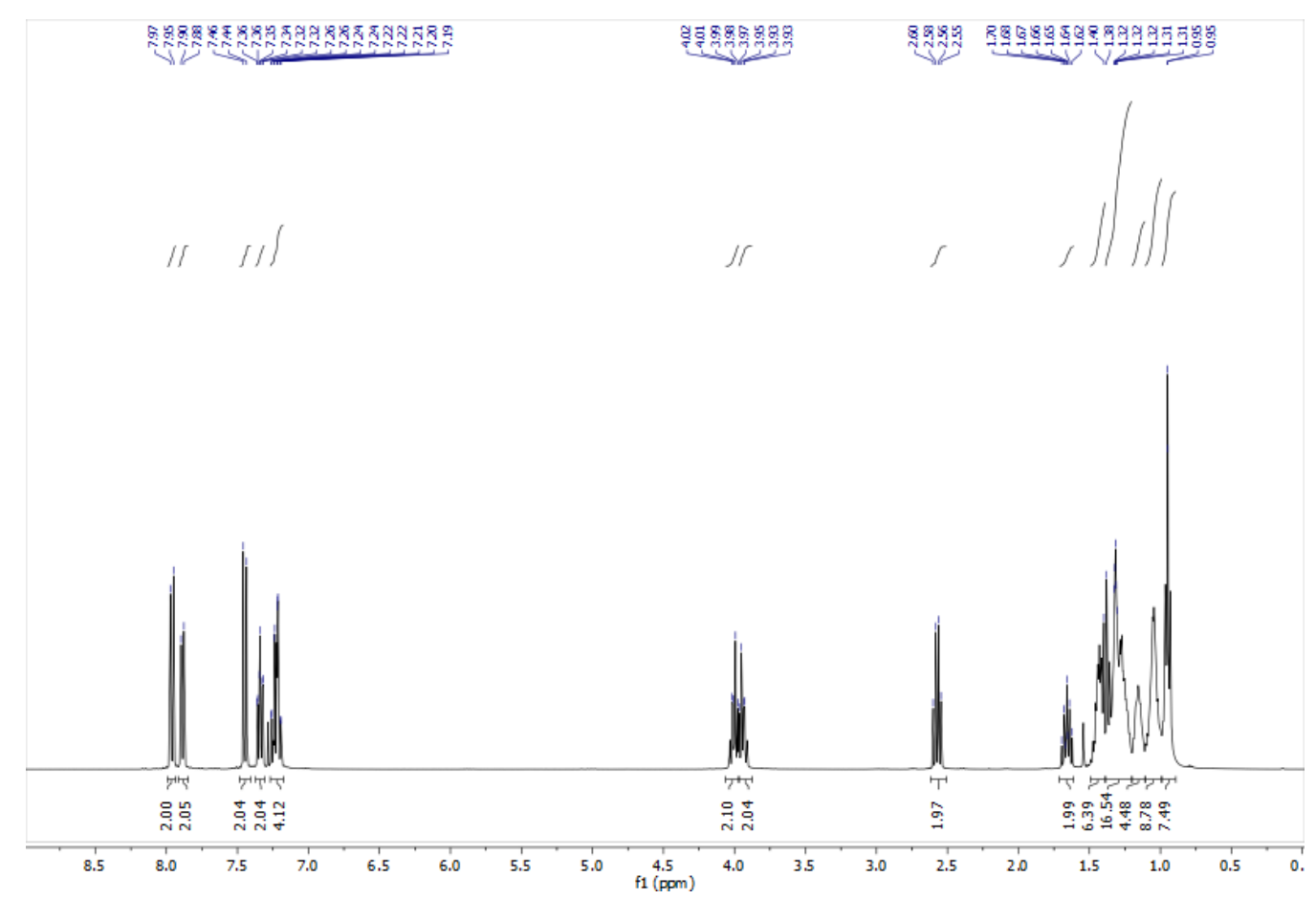

Figure S5. $\quad{ }^{1} \mathrm{H}$ NMR spectrum of $(R)-\mathbf{3}((S)-\mathbf{3}$ is identical).

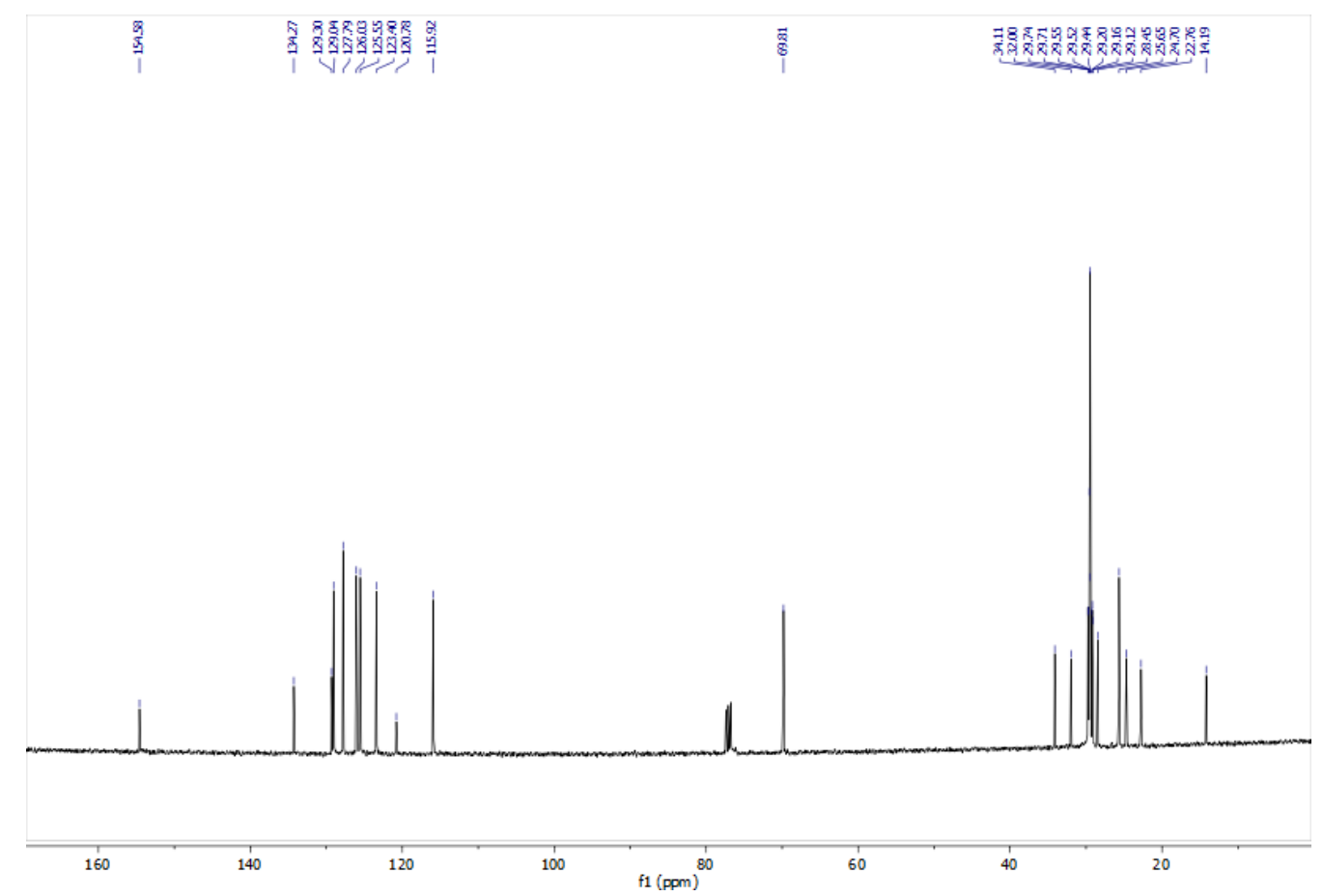

Figure S6. ${ }^{13} \mathrm{C}$ NMR spectrum of $(R)-3((S)-3$ is identical). 


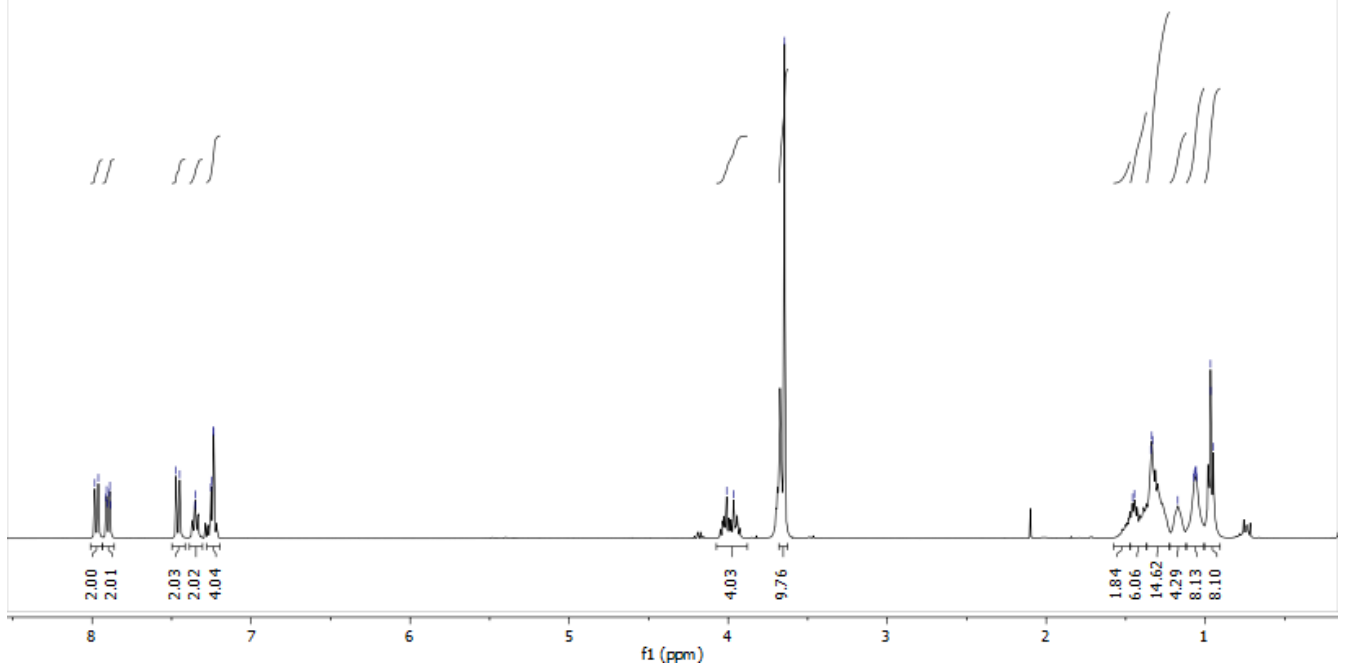

Figure S7. ${ }^{1} \mathrm{H}$ NMR spectrum of Si-(S)-3.

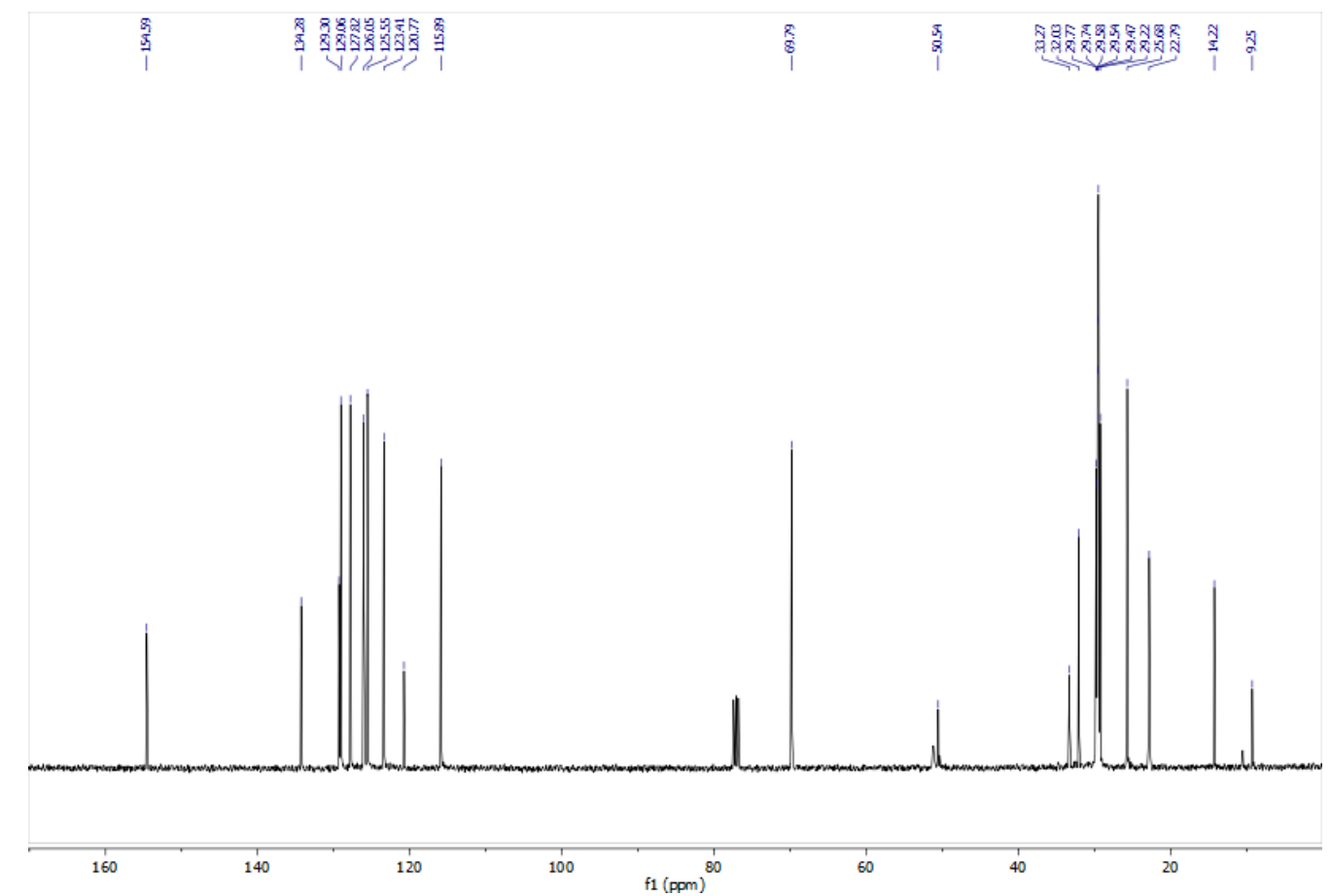

Figure S8. $\quad{ }^{13} \mathrm{C}$ NMR spectrum of Si-(S)-3.

\section{GNR Synthesis}

2.1. Synthesis method of GNRs

All glassware used for synthesis and storage of gold nanoparticles were washed with aqua regia, rinsed with 
deionized water (Millipore, resistivity $18.1 \mathrm{M} \Omega$ ), acetone, and iso-propanol and dried at $120{ }^{\circ} \mathrm{C}$ overnight. For the seed solution for the GNR synthesis $5 \mathrm{~mL}$ of $0.01 \mathrm{M} \mathrm{HAuCl}_{4}$ were mixed with $5 \mathrm{~mL}$ of $0.2 \mathrm{M} \mathrm{CTAB}$ solution in a $20 \mathrm{~mL}$ vial, and after 10 minutes stirring $0.6 \mathrm{~mL}$ of fresh, ice-cold $0.01 \mathrm{M} \mathrm{NaBH}_{4}$ was added to the vial under vigorous stirring $(1000 \mathrm{rpm})$. The color of the solution changed from yellow to light brownish. The seed solution was kept at $30^{\circ} \mathrm{C}$.

To prepare the growth solution, $1.40 \mathrm{~g} \mathrm{CTAB}$ and $0.24 \mathrm{~g} \mathrm{NaOL}$ were added to $50 \mathrm{~mL}$ warm DI water $\left(\sim 45{ }^{\circ} \mathrm{C}\right)$ in a $250 \mathrm{~mL}$ Erlenmeyer flask $\left(0.04 \mathrm{M}\right.$ in the final growth solution). Then, a solution of $3.6 \mathrm{~mL}$ of $\mathrm{AgNO}_{3}(0.01 \mathrm{M})$ was added when the temperature reached $\left(\sim 35^{\circ} \mathrm{C}\right)$. The mixture was kept undisturbed for $15 \mathrm{~min}$, and then 5 $\mathrm{mL}$ of a $0.01 \mathrm{M} \mathrm{HAuCl}_{4}$ solution in $50 \mathrm{~mL} \mathrm{DI}$ water was added to the mixture. After 90 min the solution became colorless. Then, $2 \mathrm{~mL}$ of $12.1 \mathrm{M} \mathrm{HCl}$ added to adjust the $\mathrm{pH}$. After another 15 minutes $0.25 \mathrm{~mL}(0.1 \mathrm{M})$ of ascorbic acid was added. Finally, $0.2 \mathrm{~mL}$ of the as-prepared seed was injected into the growth solution. The resultant mixture was left undisturbed at $30^{\circ} \mathrm{C}$ overnight. The final product was isolated at $13,000 \mathrm{rpm}$ for 10 minutes and subsequent removal of the supernatant. ${ }^{\text {s3-4 }}$

\subsection{Size distribution of GNRs}
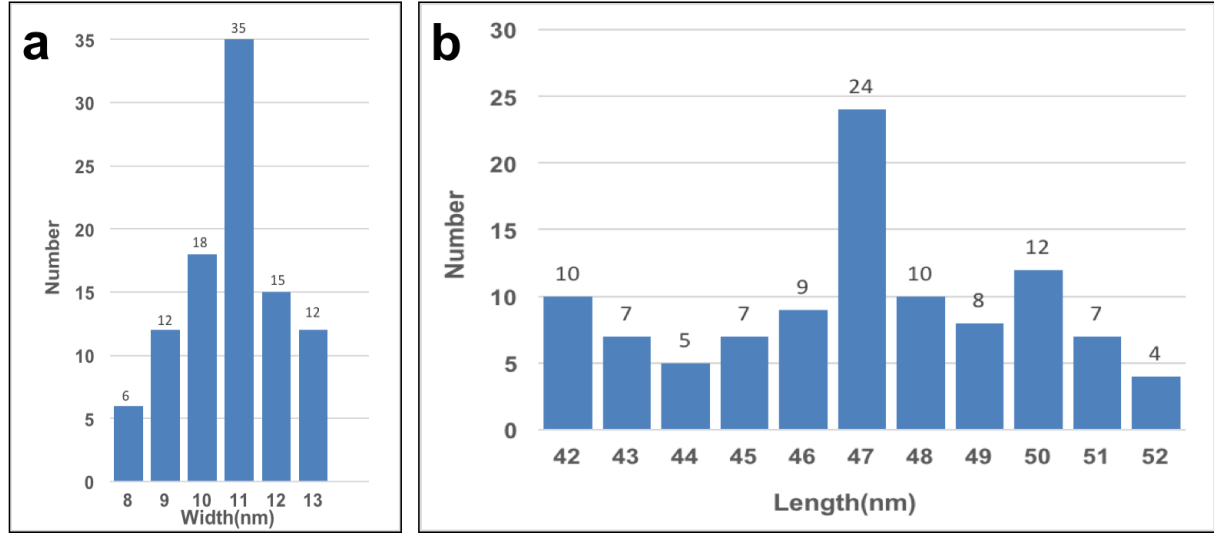

Figure S9. Size distribution of GNRs determined by TEM image analysis: (a) length distribution and (b) width distribution.

\subsection{TEM imaging of GNRS}

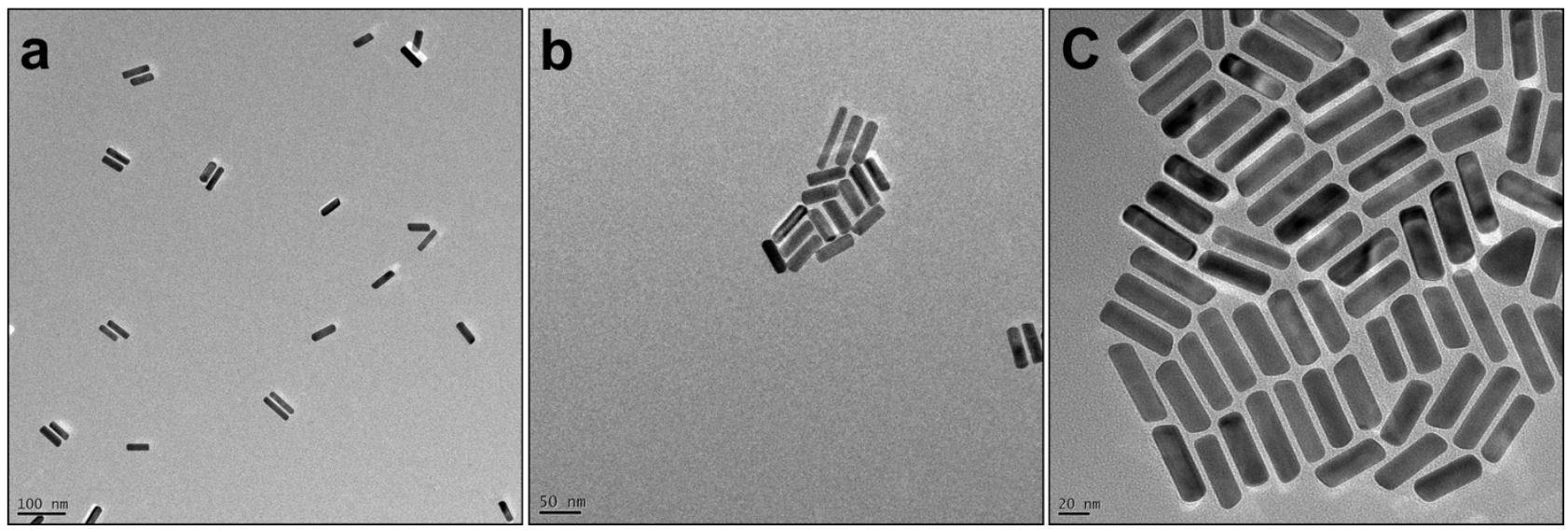

Figure S10. TEM images at different magnification: (a) $100 \mathrm{~nm}$ scale, (b) $50 \mathrm{~nm}$ scale, and (c) $20 \mathrm{~nm}$ scale. 


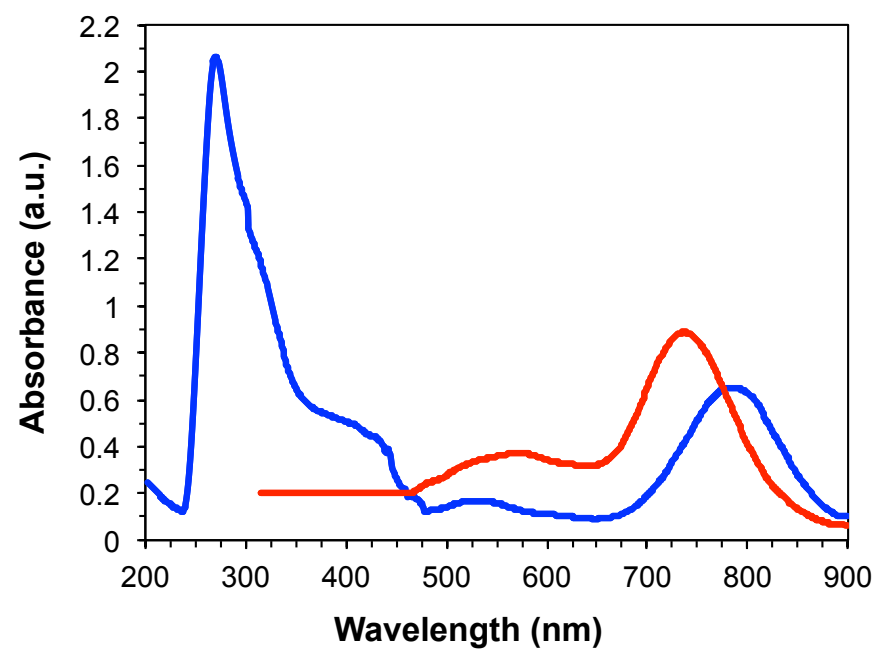

Figure S11. UV-vis-NIR spectrum of CTAB-GNRs (red spectrum) in $\mathrm{H}_{2} \mathrm{O}$ and (S)-3-GNRs in $n$-hexane (blue spectrum, representative for the entire series of binaphthyl-thiol as well as siloxane-shell-capped GNRs).

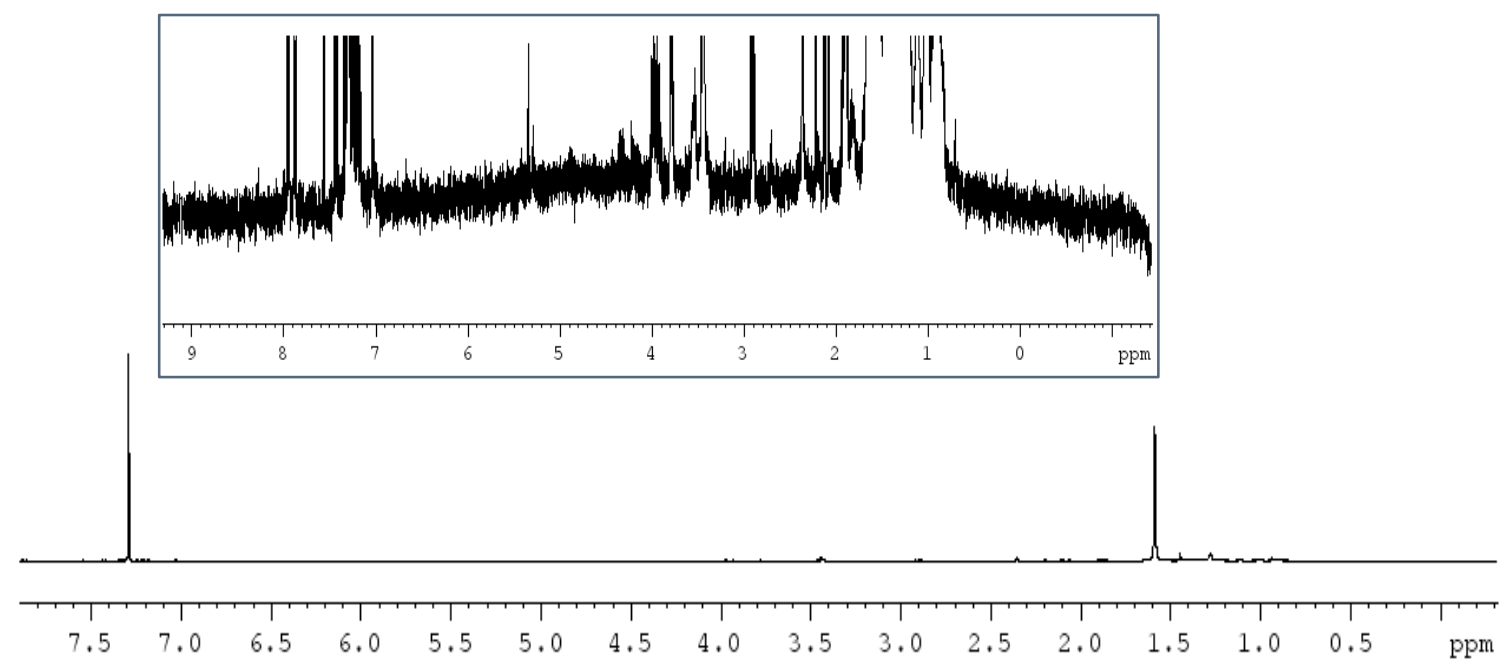

Figure S12. ${ }^{1} \mathrm{H}$ NMR spectrum of (S)-3-GNRs in $\mathrm{CDCl}_{3}$ (representative for the entire series): while the concentration of the was GNRs sufficiently high, only weak ${ }^{1} \mathrm{H}$ signals with poor signal-to-noise ratio indicating the presence of the binaphthyl ligands could be detected (see inset). 
3. Thermogravimetric Analysis (TGA) of binaphthyl-capped GNR: (S)-enantiomers
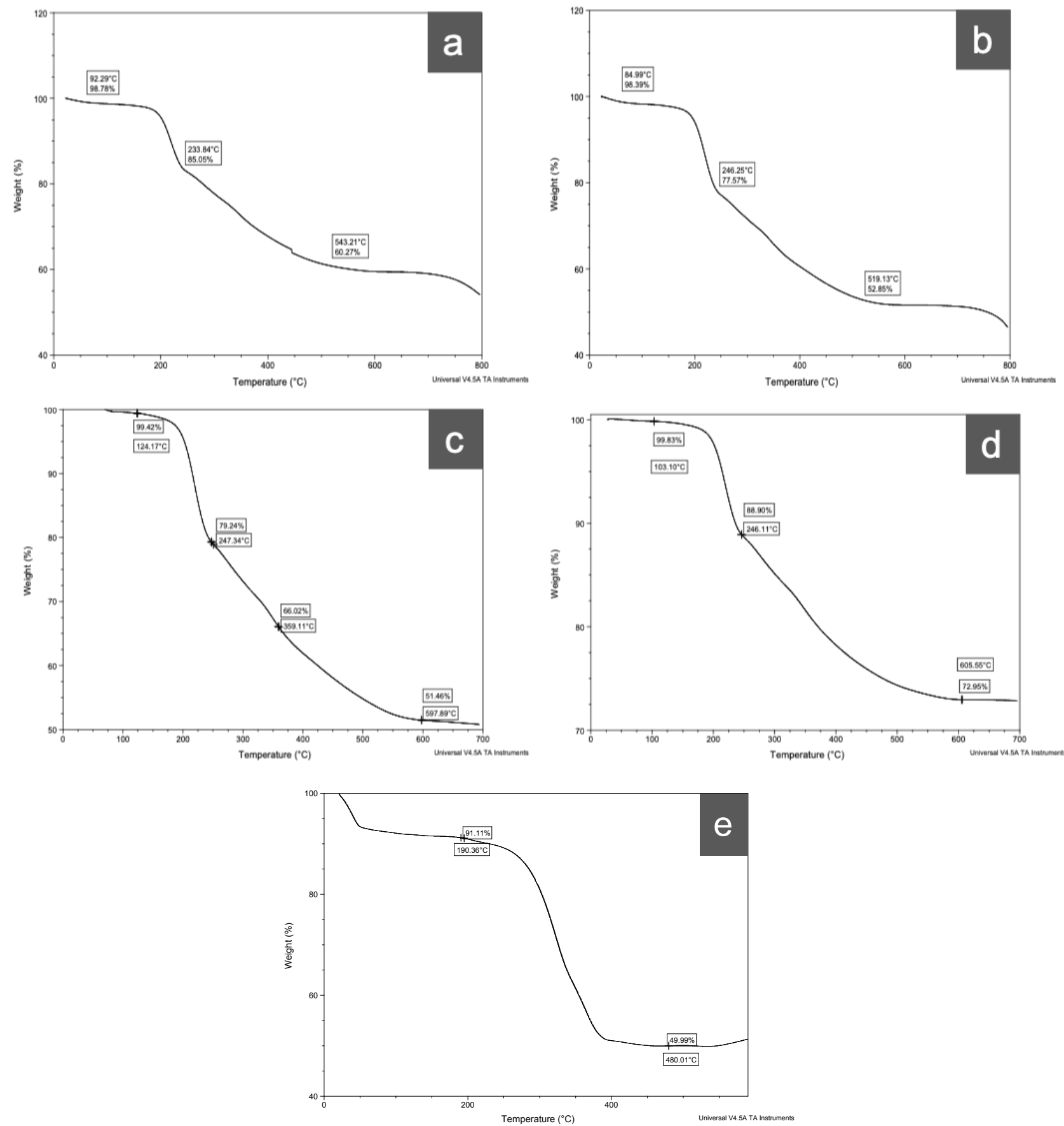

Figure S13. Determination of ligand coverage (wt.\%): Thermogravimetric analysis (TGA) plots for the binaphthyl-capped GNR samples: (a) (S)-1-GNR (using a $4.05 \mathrm{mg}$ sample; weight loss = 39.7\%), (b) (S)-2-GNR (using a $3.16 \mathrm{mg}$ sample; weight loss $=47.2 \%$ ), (c) (S)-3-GNR (using a $4.10 \mathrm{mg}$ sample; weight loss $=48.6 \%$ ), and (d) Si-(S)-3-GNR (using a 7.55 mg sample; weight loss $=28 \%$ ). Values for the $(R)$-enantiomer-capped GNRs are practically identical. (e) Chol-GNR (using a $10.85 \mathrm{mg}$ sample; after initial loss of residual solvent at about $50{ }^{\circ} \mathrm{C}$ the weight loss $=41.1 \%$ ). 


\section{a}
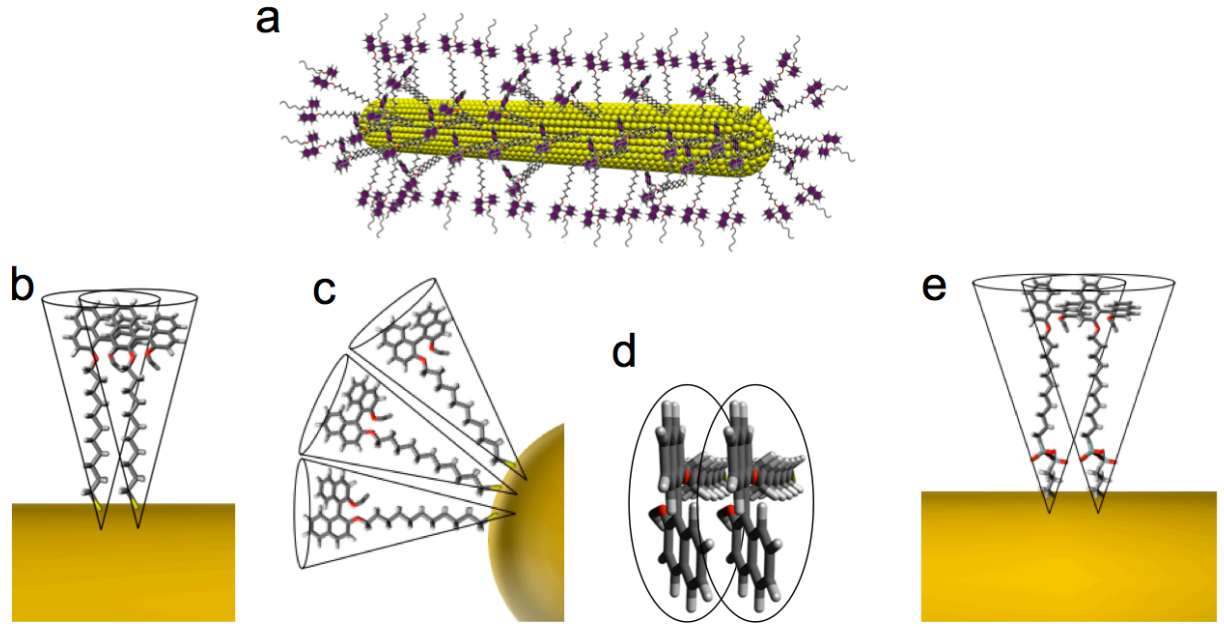

Figure S14. Model used for the calculation of the ligand surface coverage of the GNRs shown schematically in (a): (b) GNRs capped with binaphthyl thiol ligands in cisoid conformation (as observed in solution) along the nanorod and (c) taking the curvature of the GNRs into consideration. (d) Potential packing of binaphthyl ligands (top view). (e) GNRs capped with binaphthyl-siloxane network. The siloxane network ( $\cdots \mathrm{O}-\mathrm{Si}-\mathrm{O}-\mathrm{Si}-\mathrm{O} \cdots)$ increases the spacing between adjacent binaphthyl ligands, which, in turn, results in overall lower ligand coverage that is confirmed by the experimental TGA data. Assuming dense monolayer packing and the above depicted geometrical considerations led to the calculated weight\% data listed in Table 1. For further details, see calculations in references [S2] and [S4].

The chemical structures of the commercially available nematic liquid crystal hosts COC, R811, and ZLI-4572:

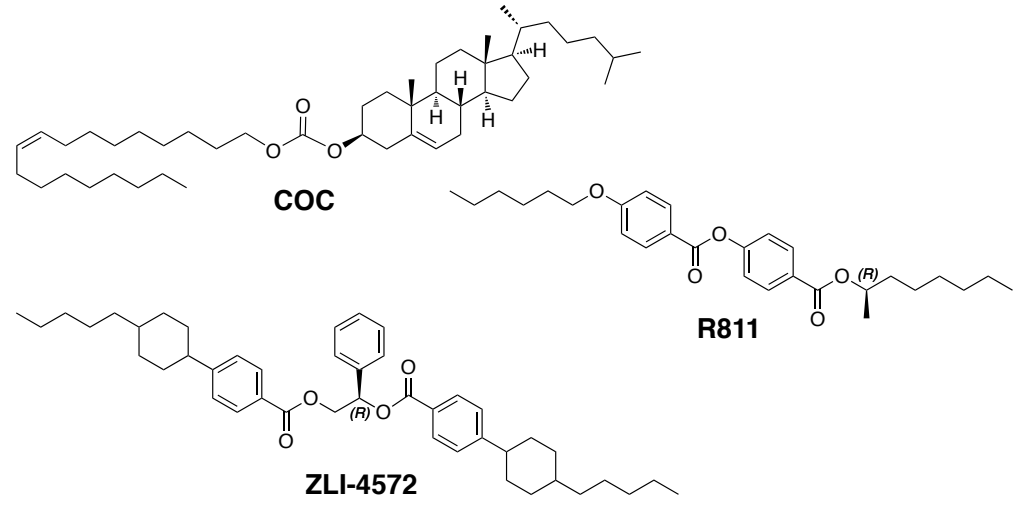

Scheme S2. Chemcial structures of COC, R811, and ZLI-4572. 


\section{SECTION S2: CHARACTERIZATION OF INDUCED N*-LC PHASES}

\section{POM studies of induced $N^{*}$ LC phase}

\subsection{Preparation of substrates, cells, and lenses}

To measure $p$ of the induced $N^{*}$-LC phases lens measurements are used. These are fabricated by using a pre-cleaned glass substrates, on which polyimide PI2555 is spin-coated, baked, and rubbed to give strong planar anchoring and the same was performed on various plano-convex lenses. These substrates are then assembled unidirectionally by placing a drop of the $\mathrm{N}^{*}$-LC mixture on the flat substrate and placing the lens on top. All measurements were done at $25{ }^{\circ} \mathrm{C}$. Additional methods used to determine $p$ measured the distances between either birefringent or dark domains in either homeotropic cells or cells with a free surface (air as top surface). Fingerprint textures were obtained in homeotropic cells constructed using two cleaned glass substrates spin coated with polyimide SE1211, and baked to provide strong homeotropic anchoring. Cells were assembled with a cell gap of $20 \mu \mathrm{m}$. After filling the cells with the N-LC/GNR mixtures by capillary force, they were sealed with epoxy adhesive. We used a microruler (calibrated with the microscope image capturing software QCapture Pro 6.0) to measure the distances between dark stripes. Free surface preparations employed cleaned, but otherwise untreated glass substrates favoring degenerate planar anchoring, onto which one drop of the N-LC/GNR mixtures was placed. The top boundary was air, which favors homeotropic anchoring. Again, the distances between dark striations under crossed polarizers were measured using the microruler calibrated microscope software.

\section{2. (R)-1-GNR doped into 5CB - POM images}
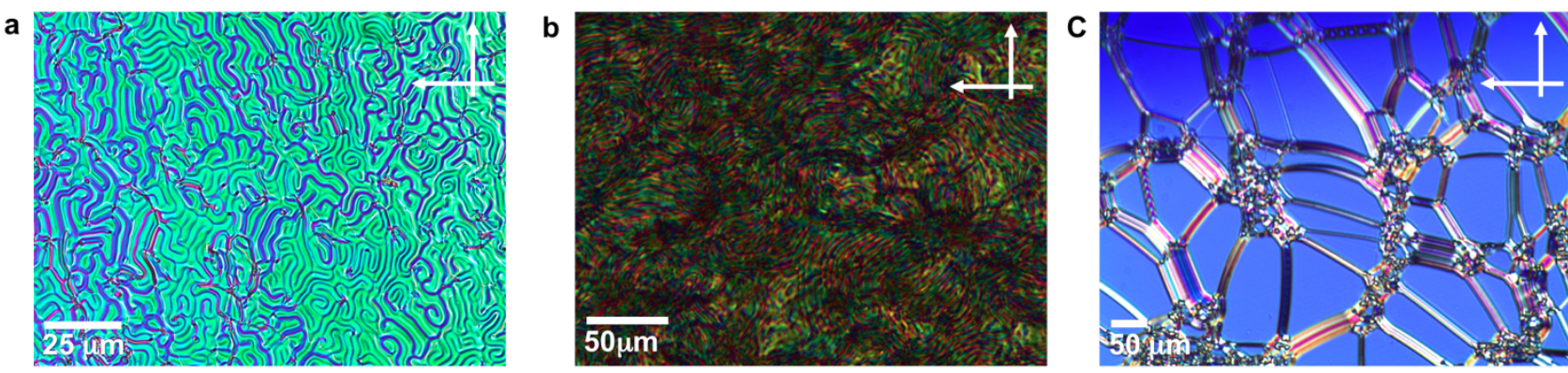

Figure S15. Characterization of induced $\mathrm{N}^{*}$-LC phase textures: all photomicrographs were captured at $20^{\circ} \mathrm{C}$ after cooling from the isotropic liquid phase (cross polarizers) for 5CB doped with $0.5 \mathrm{wt} . \%(R)$-1-GNR: (a) fingerprint texture captured using glass substrates treated to induce homeotropic boundary conditions, (b) fingerprint texture captured for free surface preparation, and (c) oily streak texture captured using glass substrates treated to induce planar boundary conditions. 


\section{3. $(R)$-2-GNR doped into $5 \mathrm{CB}-\mathrm{POM}$ images}
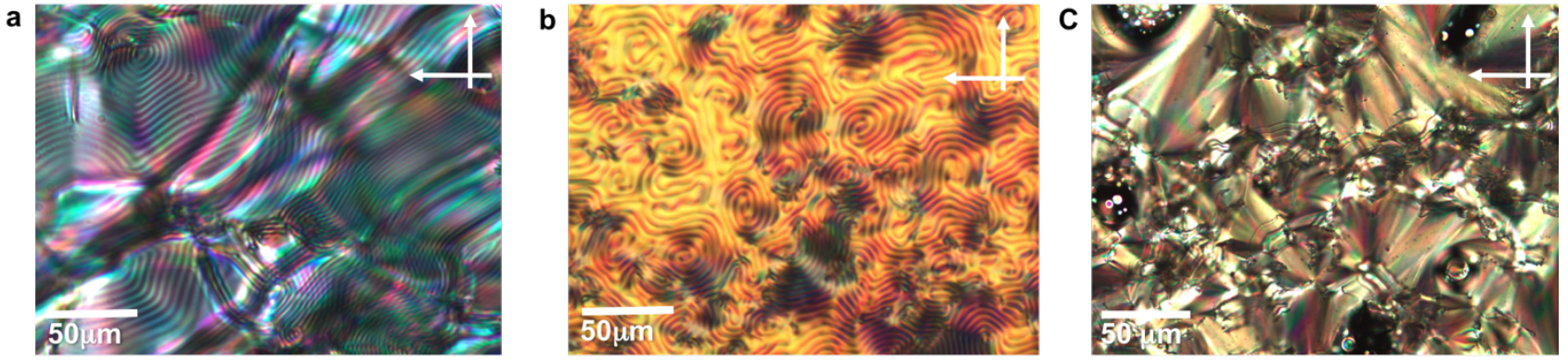

Figure S16. Characterization of induced $\mathrm{N}^{*}$-LC phase textures: all photomicrographs were captured at $20^{\circ} \mathrm{C}$ after cooling from the isotropic liquid phase (cross polarizers) for 5CB doped with $0.5 \mathrm{wt}$ \% (R)-2-GNR: (a) fingerprint texture captured using glass substrates treated to induce homeotropic boundary conditions, (b) fingerprint texture captured for free surface preparation, and (c) focal conic texture captured using glass substrates treated to induce planar boundary conditions.

\section{4. (R)-3-GNR doped into 5CB - POM images}
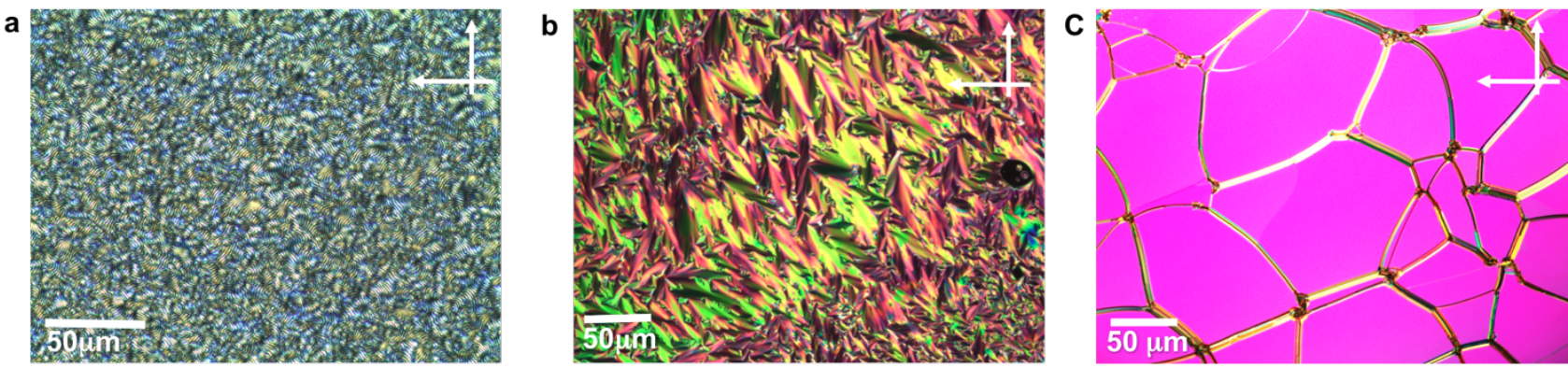

Figure S17. Characterization of induced $\mathrm{N}^{*}$-LC phase textures: all photomicrographs were captured at $20^{\circ} \mathrm{C}$ after cooling from the isotropic liquid phase (cross polarizers) for 5CB doped with $0.5 \mathrm{wt}$ \% (R)-3-GNR: (a) fingerprint texture captured using glass substrates treated to induce homeotropic boundary conditions, (b) focal conic texture captured for free surface preparation, and (c) oily streak texture captured between glass substrates with planar anchoring.

\subsection{Chol-GNR doped into $5 \mathrm{CB}-\mathrm{POM}$ images}
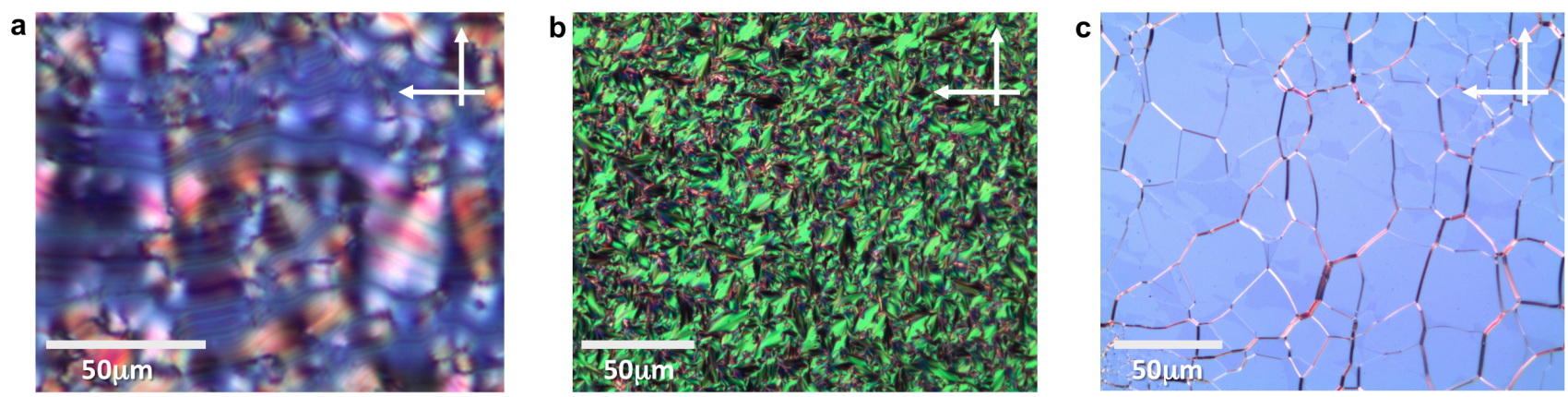

Figure S18. Characterization of induced $\mathrm{N}^{*}$-LC phase textures: all photomicrographs were captured at $20^{\circ} \mathrm{C}$ after cooling from the isotropic liquid phase (cross polarizers) for 5 CB doped with $0.5 \mathrm{wt} . \%$ Chol-GNR: (a) fingerprint texture captured using glass substrates treated to induce homeotropic boundary conditions, (b) focal conic texture captured for free surface preparation, and (c) oily streak texture captured between glass substrates with planar anchoring. 


\section{Determination of helical pitch $(p)$ from free surface preparations}

5.1. (R)-1-GNR and (S)-1-GNR doped into 5CB
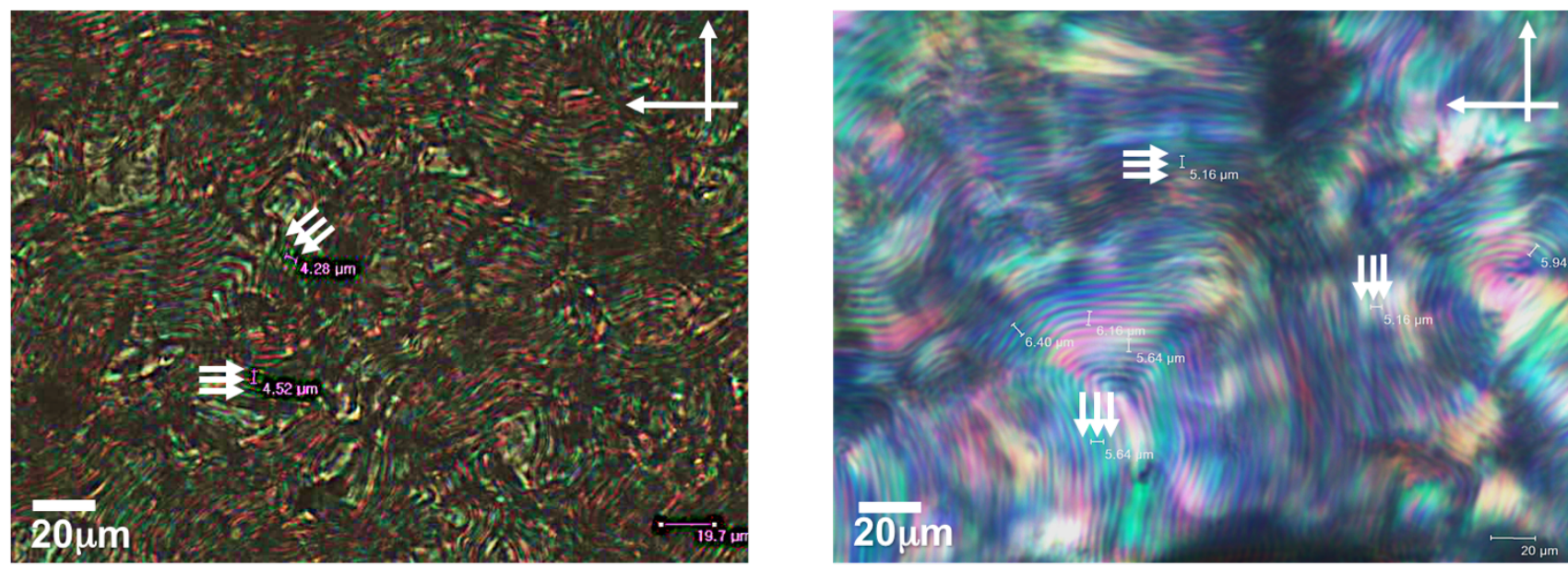

Figure S19. Polarized optical photomicrographs (crossed polarizers) obtained on cooling from the isotropic liquid phase at $20^{\circ} \mathrm{C}$ ) of the $\mathrm{N}^{*}$-LC phase induced by: (a) $0.5 \mathrm{wt} \%$ (R)-1-GNR showing fingerprint texture with $\sim 5 \mathrm{~mm}$ pitch and (b) 0.5 wt.\% (S)-1-GNR showing fingerprint with $\sim 5 \mu \mathrm{m}$ pitch.

\section{2. (R)-2-GNR and (S)-2-GNR doped into 5CB}
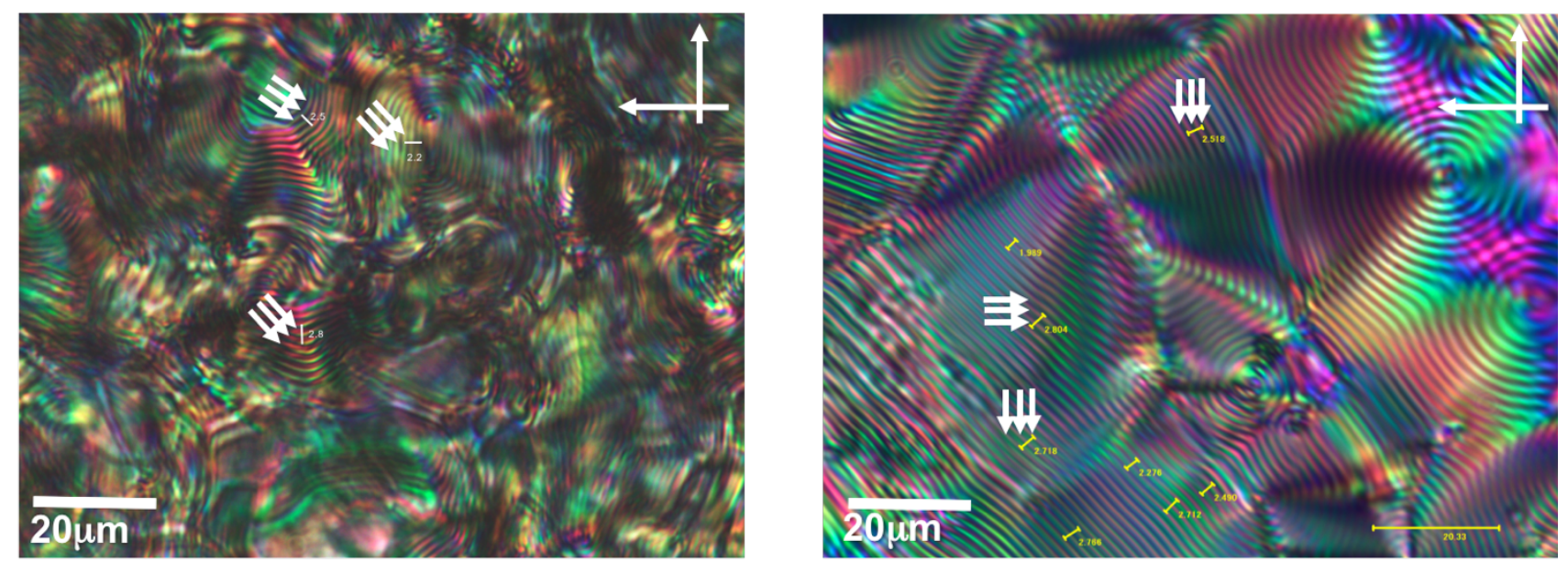

Figure S20. Polarized optical photomicrographs (crossed polarizers) obtained on cooling from the isotropic liquid phase at $20{ }^{\circ} \mathrm{C}$ ) of the $\mathrm{N}^{*}$-LC phase induced by: (a) $0.5 \mathrm{wt} . \%(R)$-2-GNR showing fingerprint texture with $\sim 2.5 \mu \mathrm{m}$ pitch and (b) 0.5 wt.\% (S)-2-GNR showing fingerprint with $\sim 2.5 \mu \mathrm{m}$ pitch. 


\section{3. (R)-3-GNR and (S)-3-GNR doped into 5CB}
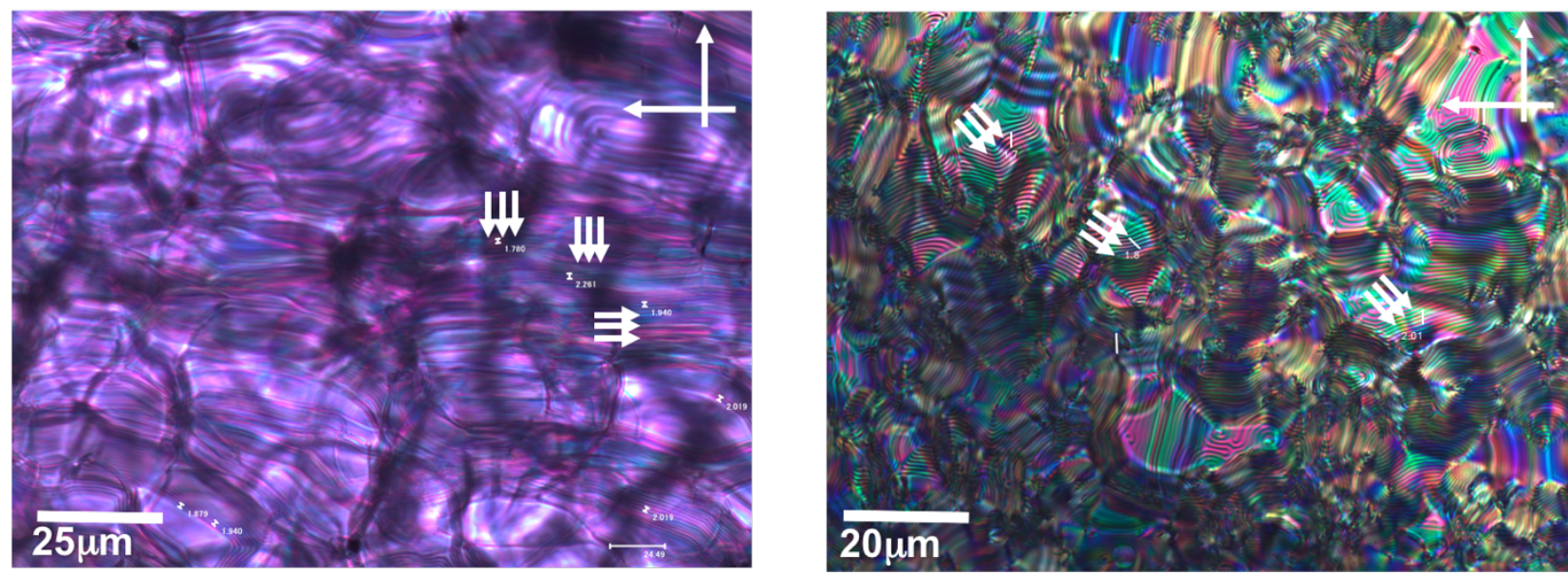

Figure S21. Polarized optical photomicrographs (crossed polarizers) obtained on cooling from the isotropic liquid phase at $20^{\circ} \mathrm{C}$ ) of the $\mathrm{N}^{*}$-LC phase induced by: (a) $0.5 \mathrm{wt}$ \% (R)-3-GNR showing fingerprint texture with $\sim 1.8 \mu \mathrm{m}$ pitch and (b) 0.5 wt.\% (S)-3-GNR showing fingerprint with $1.8 \mu \mathrm{m}$ pitch.

\subsection{Si-(S)-3-GNR doped into 5CB}

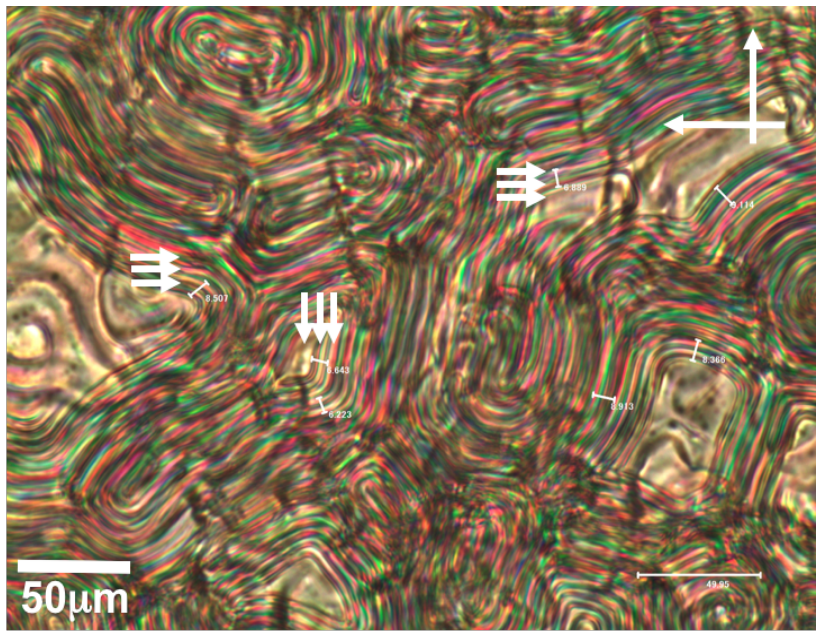

Figure S22. Polarized optical photomicrographs (crossed polarizers) obtained on cooling from the isotropic liquid phase at $20{ }^{\circ} \mathrm{C}$ ) of the $\mathrm{N}^{*}$-LC phase induced by $0.5 \mathrm{wt}$ \% $\mathrm{Si}-(\mathrm{S})-3-\mathrm{GNR}$ showing fingerprint texture with $\sim 9.1 \mu \mathrm{m}$ pitch. 


\section{Determination of handedness of the induced $N^{*} L C$ phases}

a

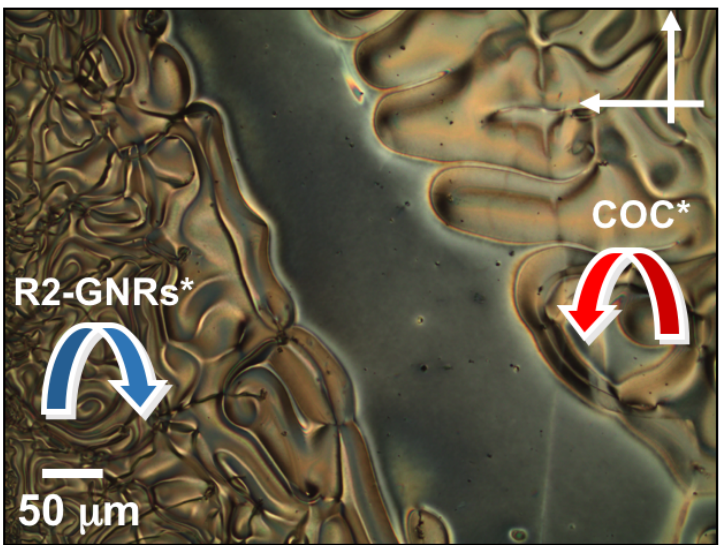

b

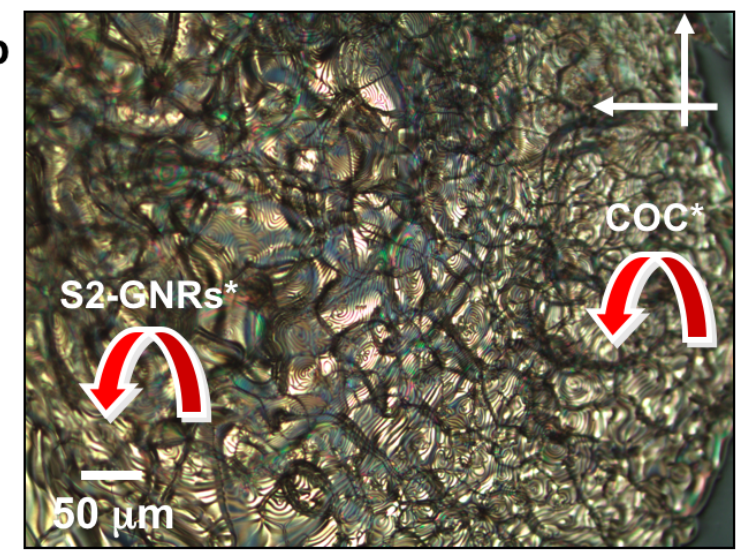

Figure S23. Characterization of induced $\mathrm{N}^{*}$-LC handedness. Contact penetration test between 5CB doped with (S)-2- and (R)-2-GNRs and $5 \mathrm{CB}$ doped with cholesteryl oleyl carbonate in glass cells at $25^{\circ} \mathrm{C}$ on cooling from the isotropic liquid phase by POM (crossed polarizers). (a) Discontinuation (achiral nematic phase in the contact zone) between $0.5 \mathrm{wt} . \%$ $(R)$-2-GNR-doped 5CB (right-handed twist in induced $\mathrm{N}^{*}$-LC phase) and COC-doped 5CB (left-handed twist in induced $\mathrm{N}^{*}$-LC phase). (b) Continuation (mixing) between (S)-2-GNR-doped 5CB (left-handed twist in induced $\mathrm{N}^{*}$-LC phase) and COC-doped 5CB (left-handed twist in induced $\mathrm{N}^{*}$-LC phase).

7. Cano wedge cells using concave lens - helical pitch, $p$, measurements

7.1. General approach to using the lens experiment

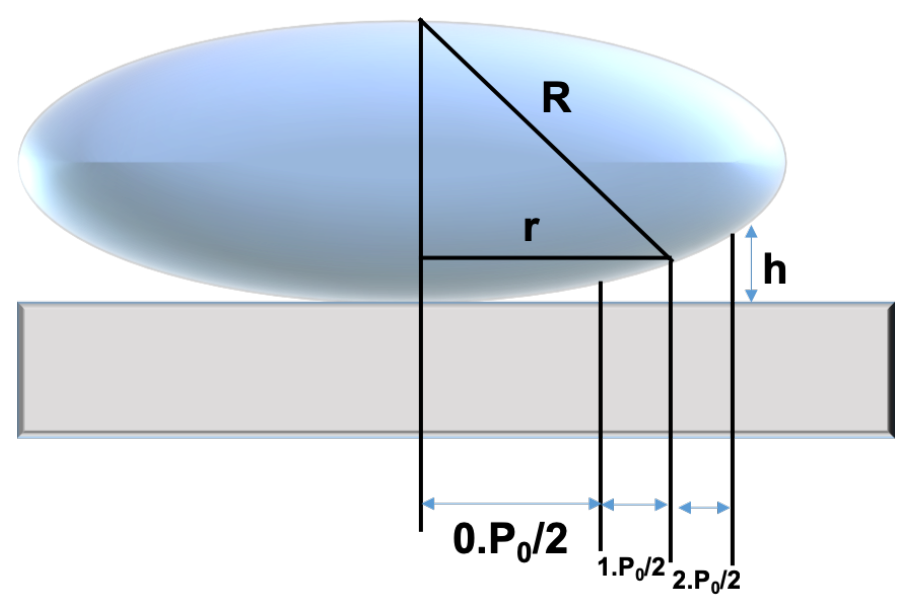

$r_{n}=R-\left(R^{2}-r_{n}^{2}\right)^{0.5}$

$\approx R-R\left(1-\frac{1}{2}\left[\frac{r_{n}}{R}\right]^{2}\right)=\frac{r_{n}^{2}}{2 R}($ when $r \ll R)$ 
As obtained in the linear wedge cell case

$h_{n}=\frac{1}{2} P_{0} n+\frac{1}{4} P_{0}$

So, we have:

$\frac{r_{n}^{2}}{2 R}=\frac{1}{2} P_{0} n+\frac{1}{4} P_{0}$

$r_{n}^{2}=\left(P_{0} R\right)_{n}+\frac{1}{2} P_{0} R$

So, we plot $r_{n}^{2}$ vs. $n$,

Slope $=P_{0} R$

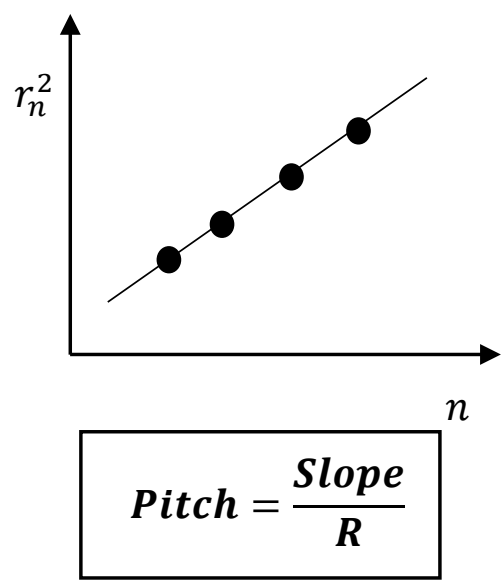




\begin{tabular}{|c|c|c|}
\hline $\begin{array}{c}\text { Number of } \\
\text { Cano lines }\end{array}$ & $\begin{array}{c}\text { Distance } \\
\text { between } \\
\text { lines }(r) / \mu m\end{array}$ & $\mathrm{r}^{2} / \mu m$ \\
\hline 1 & 368 & 135424 \\
\hline 2 & 643 & 413706 \\
\hline 3 & 813 & 660806 \\
\hline 4 & 968 & 937024 \\
\hline 5 & 1096 & 1201216 \\
\hline
\end{tabular}
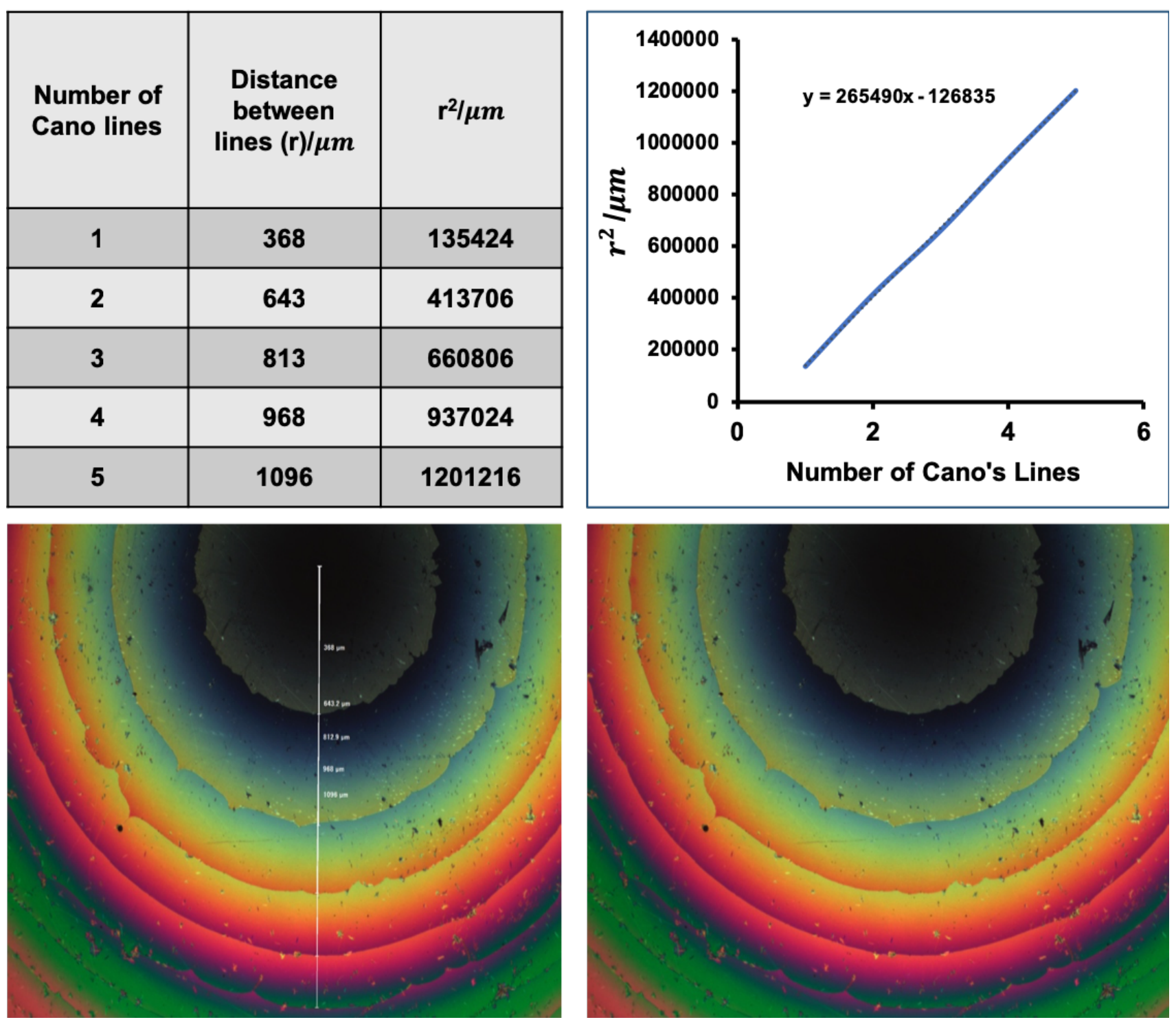

Figure S24. Determination of pitch by lens measurement: polarized optical photomicrographs (crossed polarizers, on cooling from the isotropic liquid phase at $20^{\circ} \mathrm{C}$ ) of the $\mathrm{N}^{*}$-LC phase induced by doping $0.5 \mathrm{wt} . \%(R)-1-\mathrm{GNR}$ in $5 \mathrm{CB}$ showing Cano line (slope/lens curvature); $p=5.1 \mu \mathrm{m}$. 


\section{3. (S)-1-GNR}

\begin{tabular}{|c|c|c|}
\hline $\begin{array}{c}\text { Number of } \\
\text { Cano lines }\end{array}$ & $\begin{array}{c}\text { Distance } \\
\text { between } \\
\text { lines }(\mathrm{r}) / \mu \mathrm{m}\end{array}$ & $\mathrm{r}^{2} / \mu \mathrm{m}$ \\
\hline 1 & 368 & 143792 \\
\hline 2 & 643.2 & 407554 \\
\hline 3 & 812.9 & 681615 \\
\hline 4 & 968 & 952576 \\
\hline 5 & 1096 & 1207801 \\
\hline 6 & 1219 & 1485961 \\
\hline 7 & 1328 & 1763584 \\
\hline 8 & 1418 & 2010724 \\
\hline
\end{tabular}
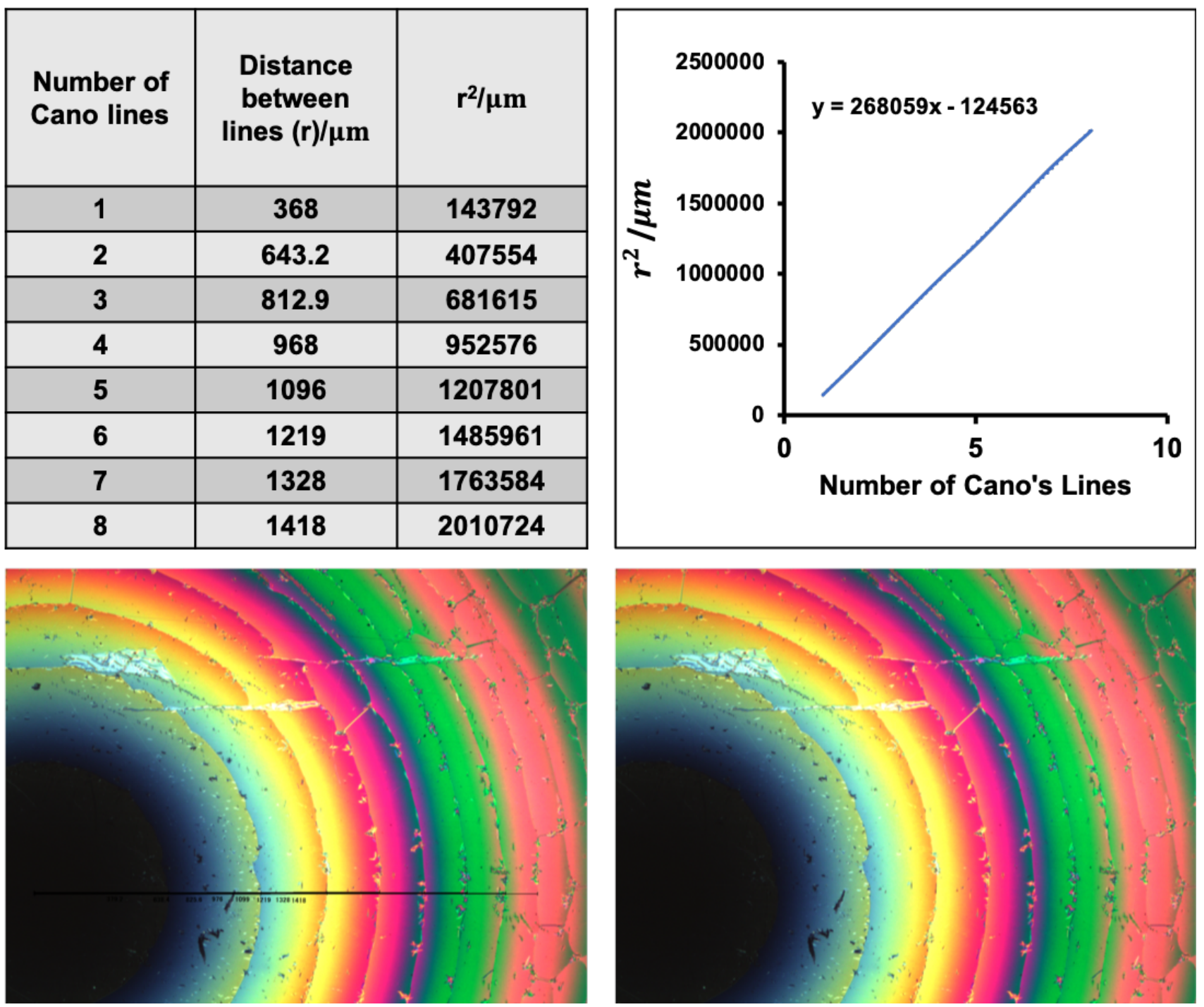

Figure S25. Determination of pitch by lens measurement: polarized optical photomicrographs (crossed polarizers, on cooling from the isotropic liquid phase at $20^{\circ} \mathrm{C}$ ) of the $\mathrm{N}^{*}$-LC phase induced by doping $0.5 \mathrm{wt} . \%(S)-1-G N R$ in 5 CB showing Cano line (slope/lens curvature); $p=5.2 \mu \mathrm{m}$. 


\begin{tabular}{|c|c|c|}
\hline $\begin{array}{c}\text { Number of } \\
\text { Cano lines }\end{array}$ & $\begin{array}{c}\text { Distance between } \\
\text { lines }(r) / \mu \mathrm{m}\end{array}$ & $\mathrm{r}^{2} / \mu \mathrm{m}$ \\
\hline 1 & 408 & 166464 \\
\hline 2 & 545 & 297025 \\
\hline 3 & 640 & 409600 \\
\hline 4 & 737 & 543169 \\
\hline 5 & 809 & 654481 \\
\hline 6 & 880 & 774400 \\
\hline 7 & 937 & 877969 \\
\hline
\end{tabular}
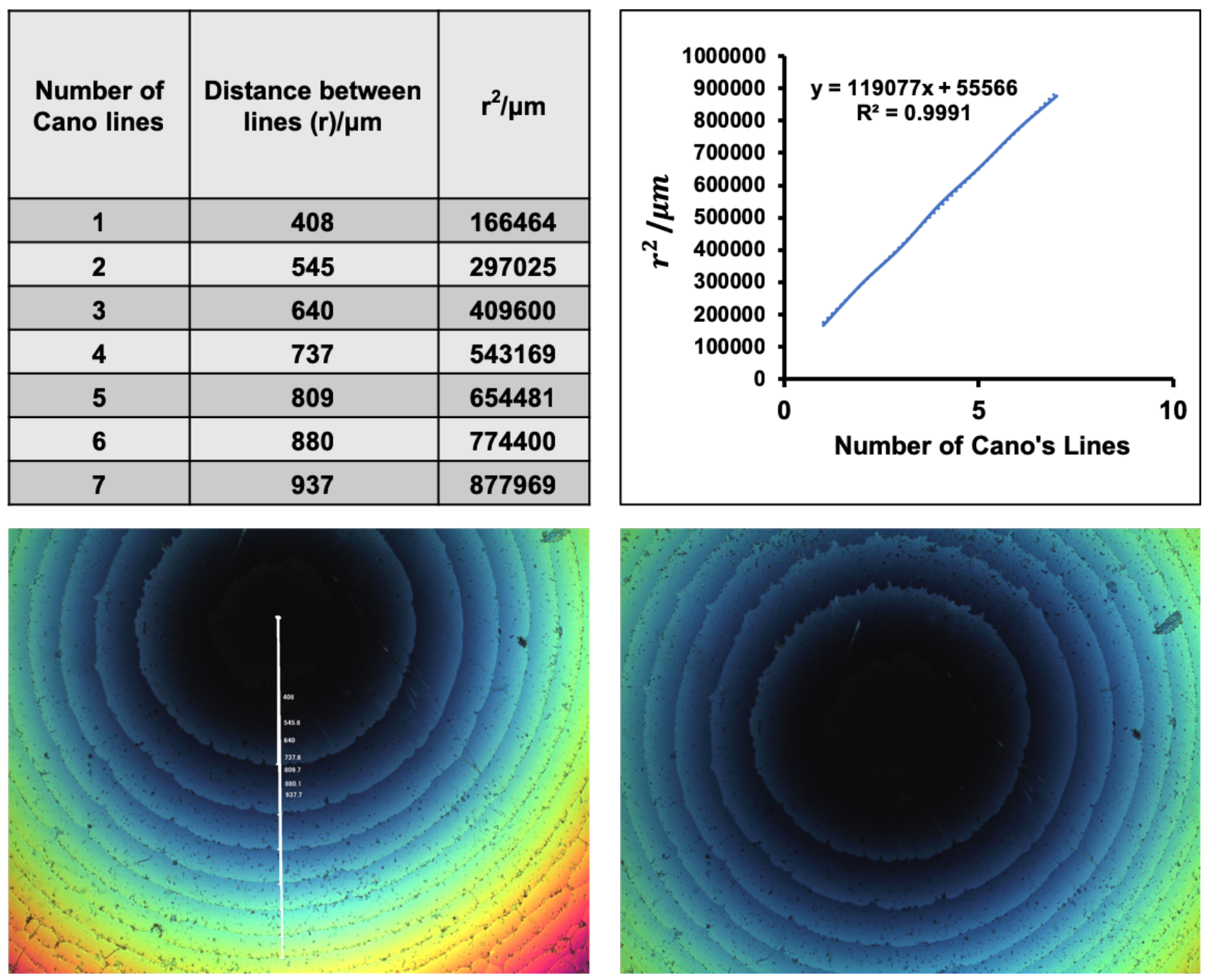

Figure S26. Determination of pitch by lens measurement: polarized optical photomicrographs (crossed polarizers, on cooling from the isotropic liquid phase at $20^{\circ} \mathrm{C}$ ) of the $\mathrm{N}^{*}$-LC phase induced by doping $0.5 \mathrm{wt} . \%(R)-2-\mathrm{GNR}$ in $5 \mathrm{CB}$ showing Cano line (slope/lens curvature); $p=2.3 \mu \mathrm{m}$. 


\section{5. (S)-2-GNR}

\begin{tabular}{|c|c|c|}
\hline $\begin{array}{l}\text { Number of } \\
\text { Cano lines }\end{array}$ & $\begin{array}{l}\text { Distance between } \\
\text { lines }(\mathbf{r}) / \mu \mathrm{m}\end{array}$ & $r^{2} / \mu m$ \\
\hline 1 & 417 & 173889 \\
\hline 2 & 542 & 293764 \\
\hline 3 & 648 & 419904 \\
\hline 4 & 736 & 541696 \\
\hline 5 & 809 & 654481 \\
\hline 6 & 888 & 788544 \\
\hline
\end{tabular}
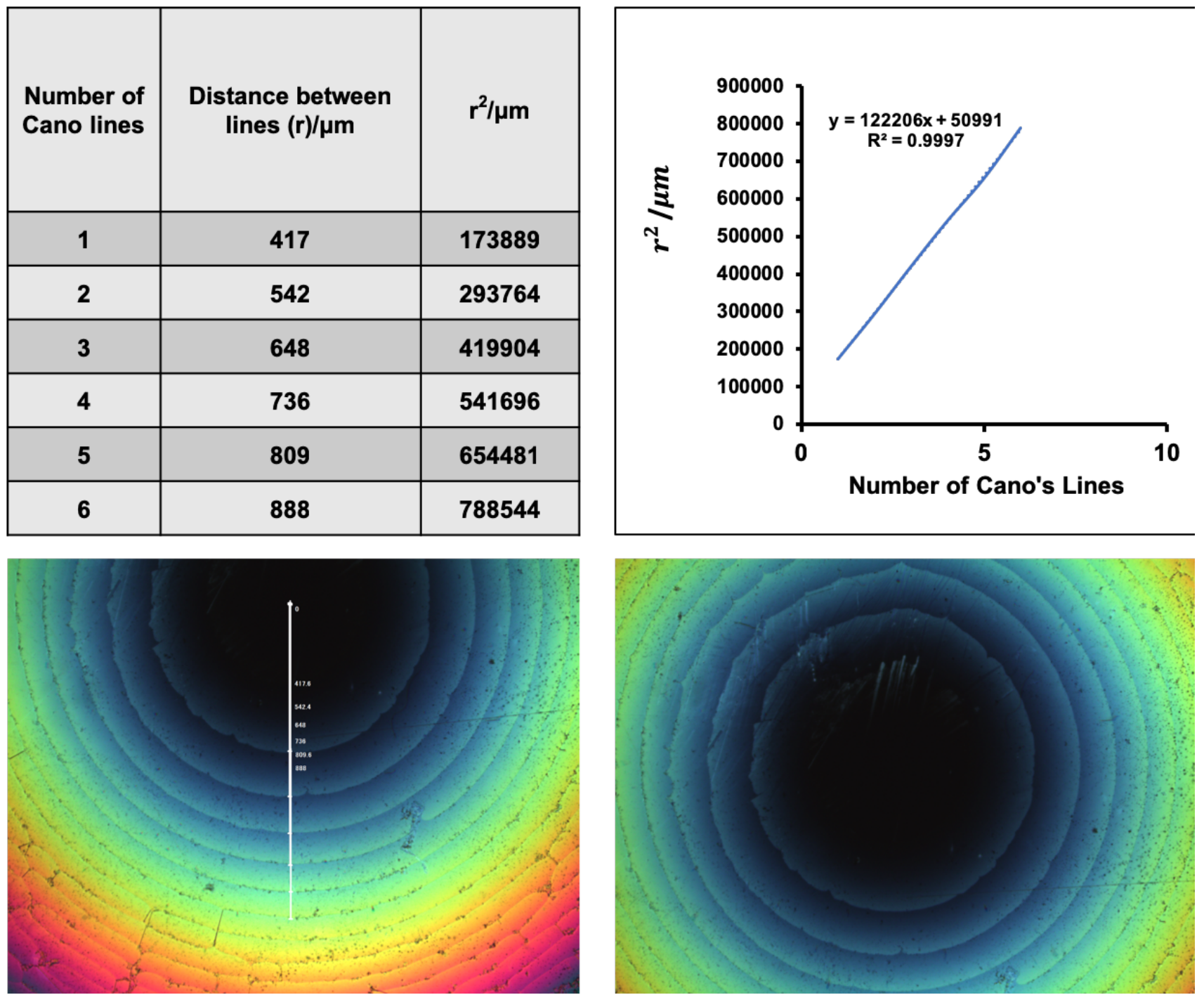

Figure S27. Determination of pitch by lens measurement: polarized optical photomicrographs (crossed polarizers, on cooling from the isotropic liquid phase at $20^{\circ} \mathrm{C}$ ) of the $\mathrm{N}^{*}$-LC phase induced by doping $0.5 \mathrm{wt} \%(S)-2-\mathrm{GNR}$ in 5 CB showing Cano line (slope/lens curvature); $p=2.4 \mu \mathrm{m}$. 


\begin{tabular}{|c|c|c|}
\hline $\begin{array}{c}\text { Number of } \\
\text { Cano lines }\end{array}$ & $\begin{array}{c}\text { Distance } \\
\text { between } \\
\text { lines (r)/ } \mu \mathrm{m}\end{array}$ & $\mathrm{r}^{2} / \mu \mathrm{m}$ \\
\hline 1 & 211 & 44521 \\
\hline 2 & 288 & 82944 \\
\hline 3 & 359 & 128881 \\
\hline 4 & 413 & 170569 \\
\hline 5 & 457 & 208849 \\
\hline 6 & 516 & 266256 \\
\hline 7 & 557 & 310249 \\
\hline 8 & 586 & 343396 \\
\hline 9 & 615 & 378225 \\
\hline
\end{tabular}
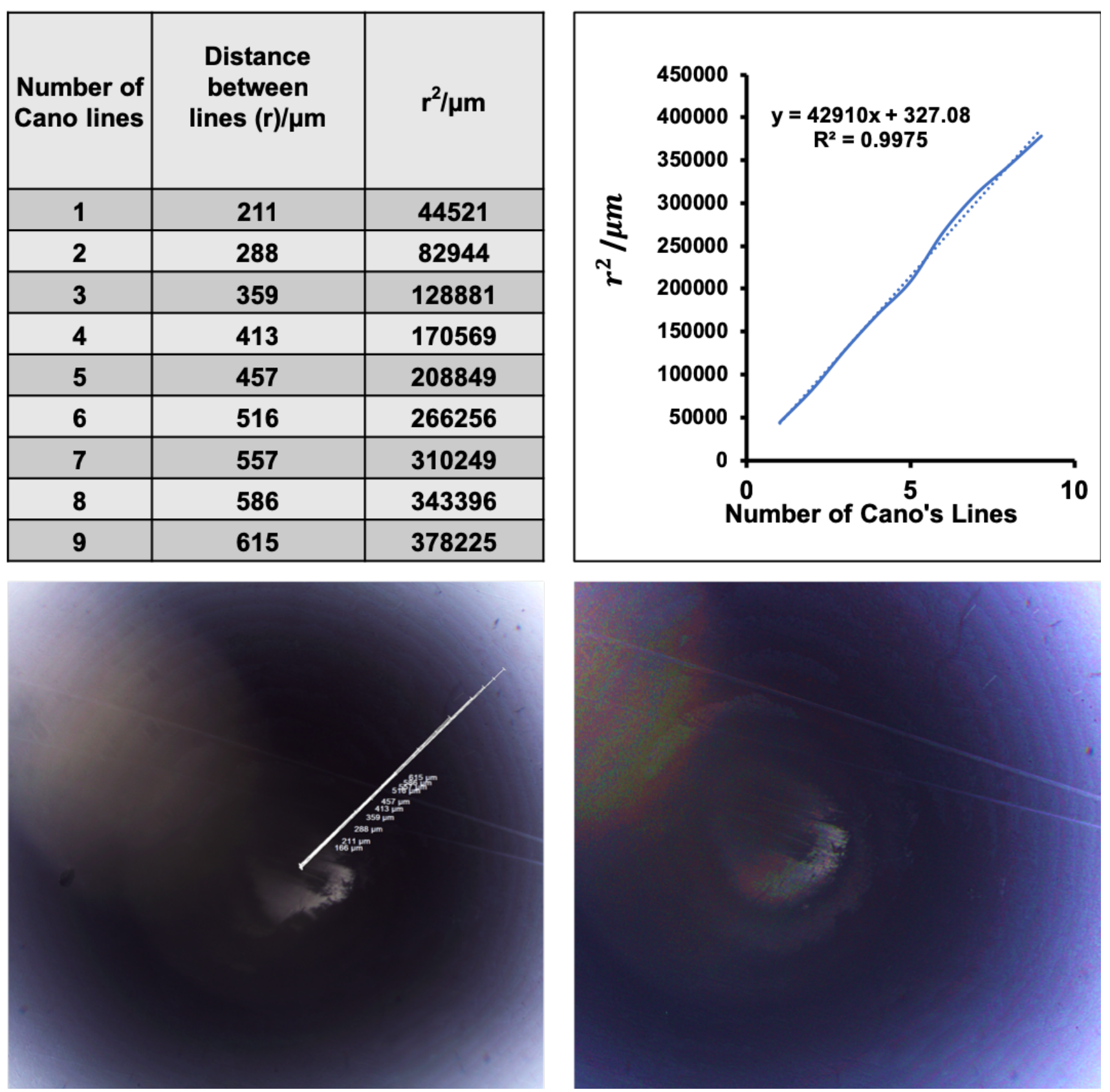

Figure S28. Determination of pitch by lens measurement: polarized optical photomicrographs (crossed polarizers, on cooling from the isotropic liquid phase at $20^{\circ} \mathrm{C}$ ) of the $\mathrm{N}^{*}$-LC phase induced by doping $0.5 \mathrm{wt} . \%(R)-3-\mathrm{GNR}$ in $5 \mathrm{CB}$ showing Cano line (slope/lens curvature); $p=0.9 \mu \mathrm{m}$. 


\section{7. (S)-3-GNR}

\begin{tabular}{|c|c|c|}
\hline $\begin{array}{c}\text { Number of } \\
\text { Cano lines }\end{array}$ & $\begin{array}{c}\text { Distance between } \\
\text { lines }(\mathrm{r}) / \mu \mathrm{m}\end{array}$ & $\mathrm{r}^{2} / \mu \mathrm{m}$ \\
\hline 1 & 338.9 & 114853.21 \\
\hline 2 & 395 & 156025 \\
\hline 3 & 450.6 & 203040.36 \\
\hline 4 & 494.9 & 244926.01 \\
\hline 5 & 558.5 & 311922.25 \\
\hline 6 & 595.8 & 354977.64 \\
\hline 7 & 636.5 & 405132.25 \\
\hline
\end{tabular}
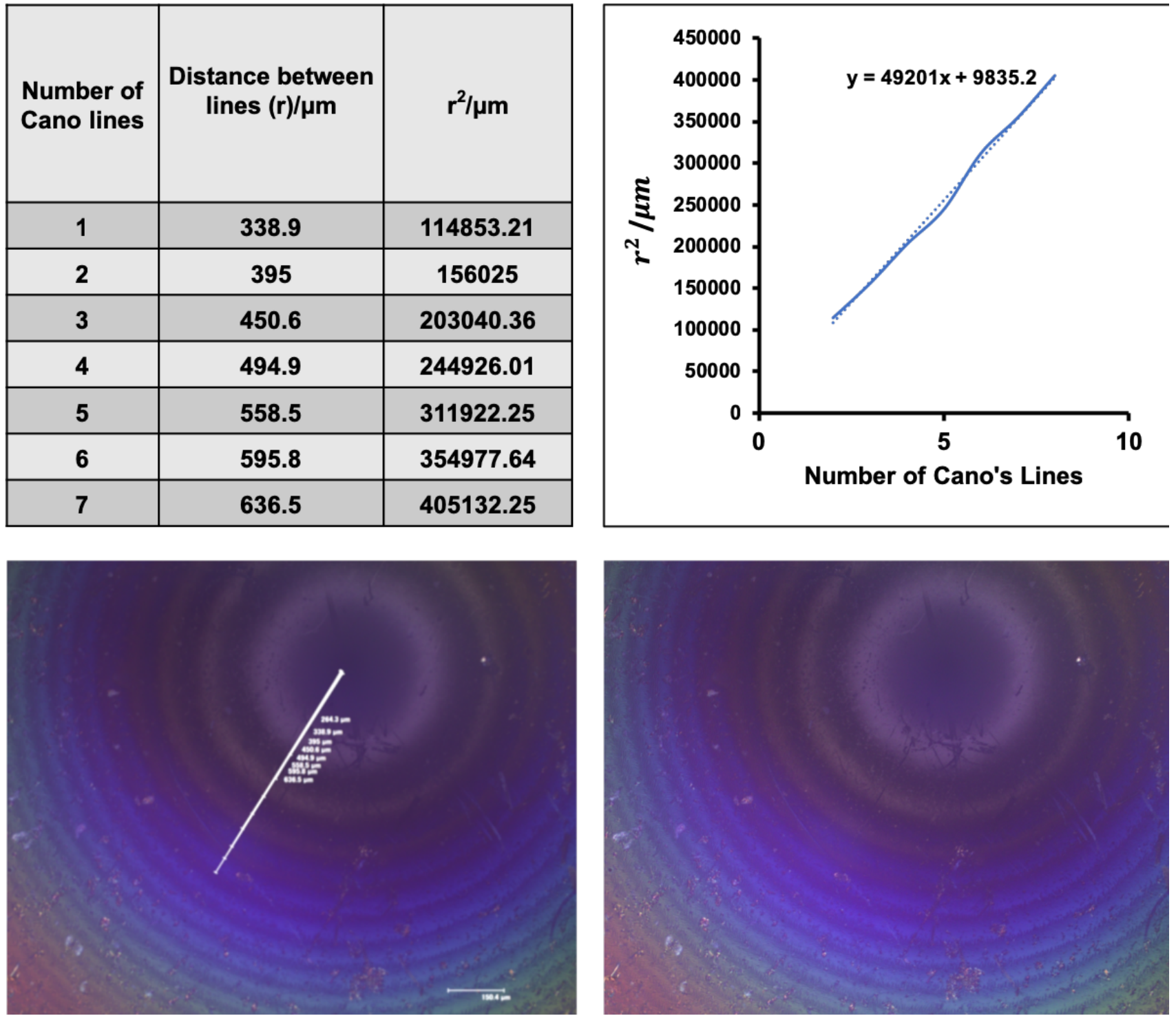

Figure S29. Determination of pitch by lens measurement: polarized optical photomicrographs (crossed polarizers, on cooling from the isotropic liquid phase at $20^{\circ} \mathrm{C}$ ) of the $\mathrm{N}^{*}$-LC phase induced by doping $0.5 \mathrm{wt} . \%(S)-3-G N R$ in 5 CB showing Cano line (slope/lens curvature); $p=0.8 \mu \mathrm{m}$. 


\subsection{Si-(S)-3-GNR}

\begin{tabular}{|c|c|c|}
\hline $\begin{array}{l}\text { Number of } \\
\text { Cano lines }\end{array}$ & $\begin{array}{c}\text { Distance between } \\
\text { lines }(r) / \mu \mathrm{m}\end{array}$ & $r^{2} / \mu m$ \\
\hline 1 & 528 & 278784 \\
\hline 2 & 906 & 821198 \\
\hline 3 & 1158 & 1340964 \\
\hline 4 & 1359 & 1846881 \\
\hline 5 & 1539 & 2368521 \\
\hline
\end{tabular}
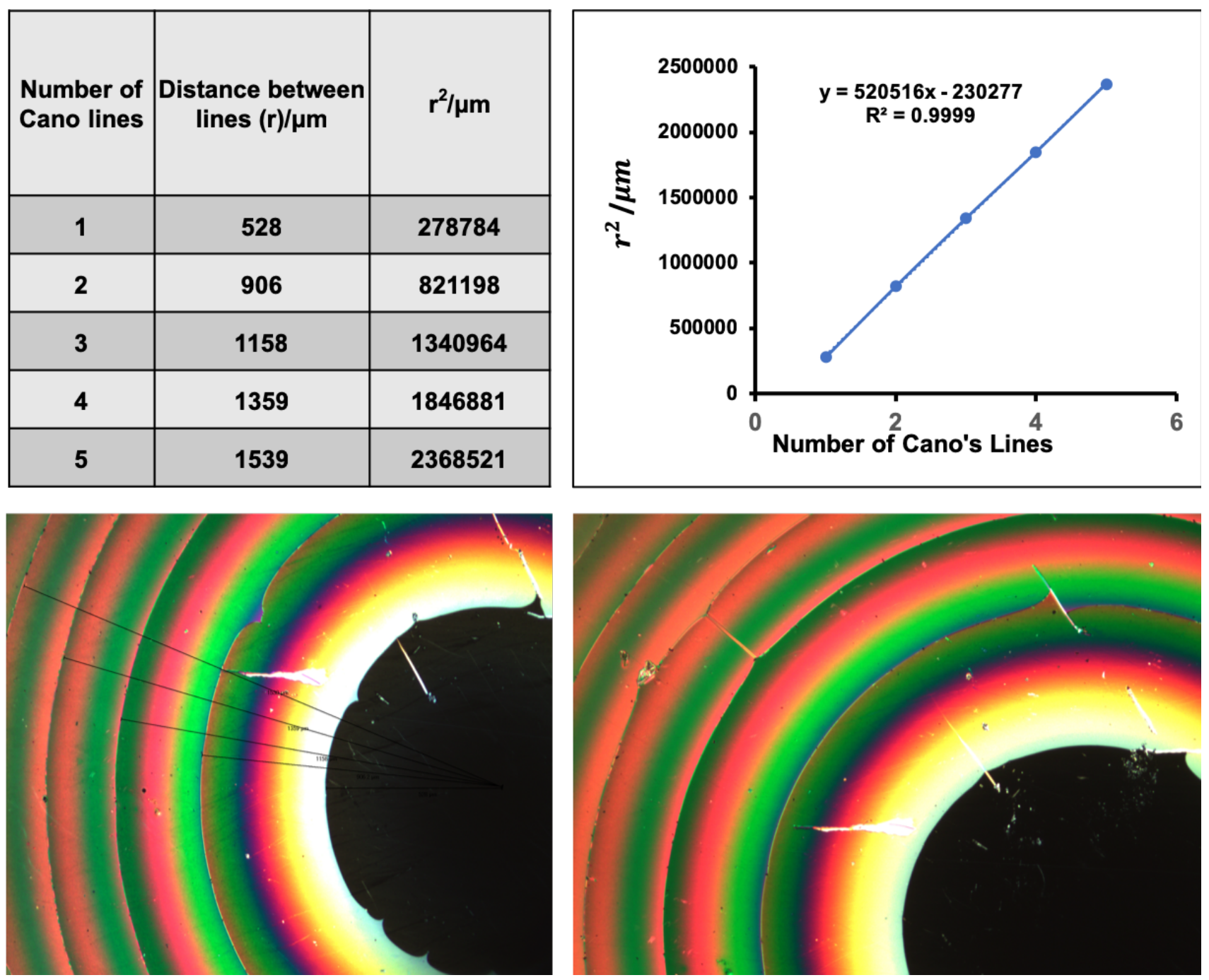

Figure S30. Determination of pitch by lens measurement: polarized optical photomicrographs (crossed polarizers, on cooling from the isotropic liquid phase at $20^{\circ} \mathrm{C}$ ) of the $\mathrm{N}^{*}$-LC phase induced by doping $0.5 \mathrm{wt} . \% \mathrm{Si}-(\mathrm{S})-3-\mathrm{GNR}$ in $5 \mathrm{CB}$ showing Cano line (slope/lens curvature); $p=10.1 \mu \mathrm{m}$. 


\subsection{Chol-GNR}

\begin{tabular}{|c|c|c|}
\hline $\begin{array}{l}\text { Number of } \\
\text { Cano lines }\end{array}$ & $\begin{array}{c}\text { Distance } \\
\text { between } \\
\text { lines }(r) / \mu m\end{array}$ & $r^{2} / \mu m$ \\
\hline 1 & 198 & 39204 \\
\hline 2 & 274 & 75076 \\
\hline 3 & 372 & 138384 \\
\hline 4 & 443 & 196249 \\
\hline 5 & 507 & 257049 \\
\hline 6 & 558 & 311364 \\
\hline 7 & 605 & 366025 \\
\hline 8 & 658 & 432964 \\
\hline
\end{tabular}
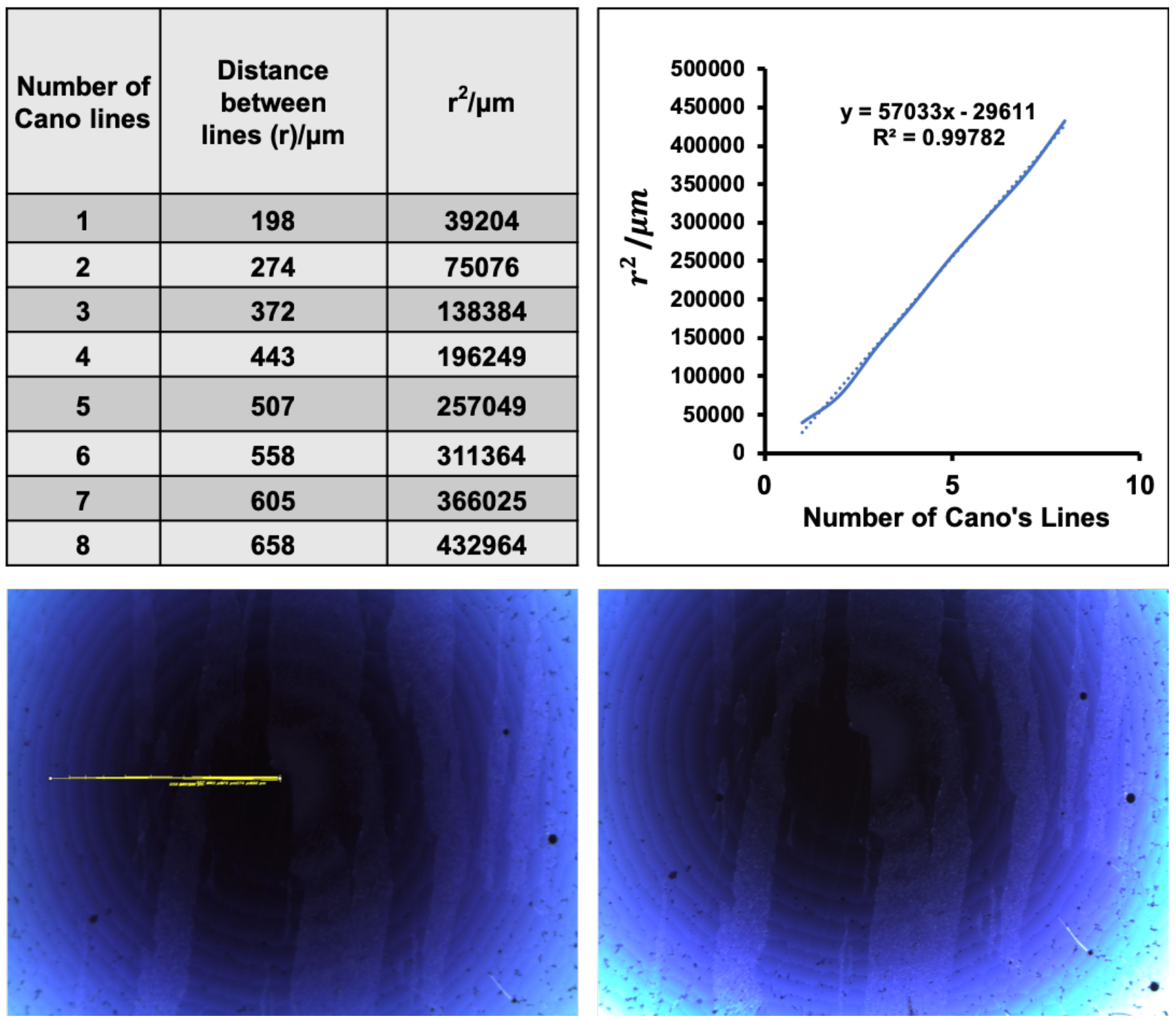

Figure S31. Determination of pitch by lens measurement: polarized optical photomicrographs (crossed polarizers, on cooling from the isotropic liquid phase at $20^{\circ} \mathrm{C}$ ) of the $\mathrm{N}^{*}$-LC phase induced by doping $0.5 \mathrm{wt} . \%$ Chol-S-GNR in 5 CB showing Cano line (slope/lens curvature); $p=1.1 \mu \mathrm{m}$. 
8. Thin film ICD spectra of the induced $N^{*}$-LC phase by doping 5CB with $(R)$-binaphthyl-capped GNRs
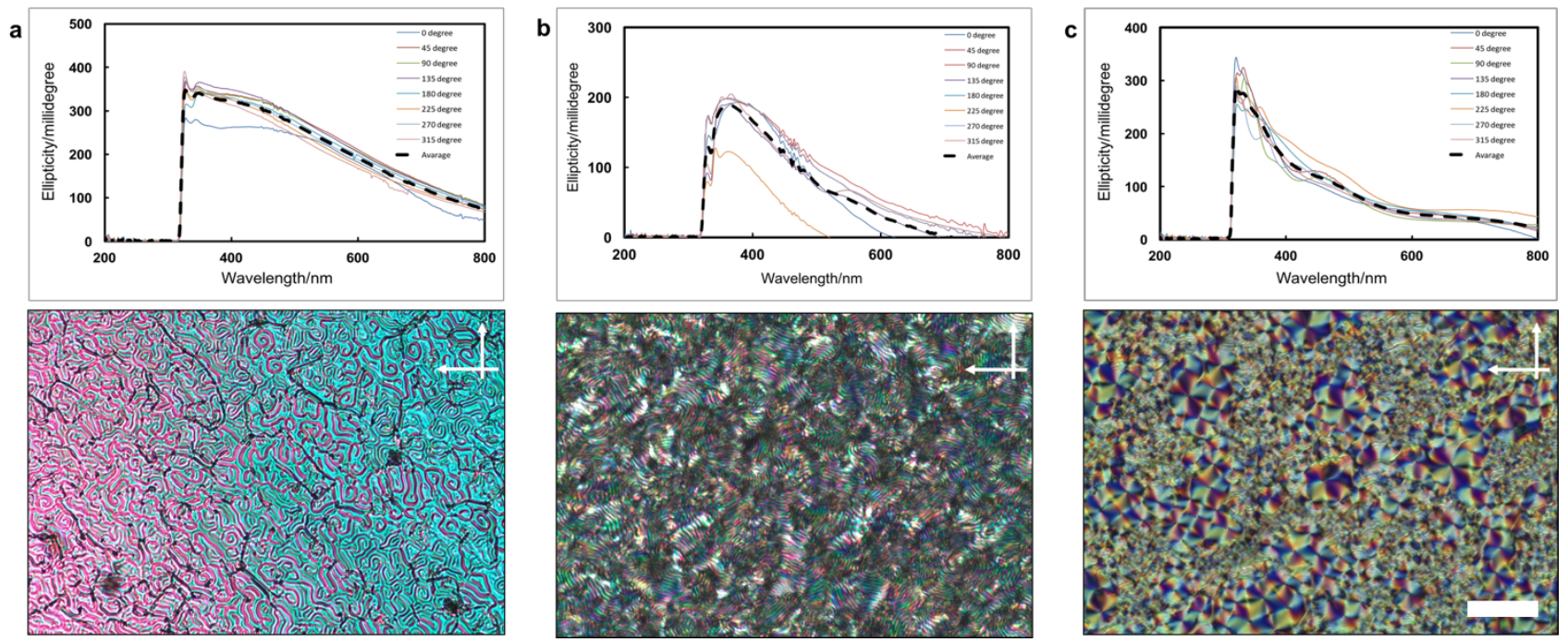

Figure S32. Induced circular dichroism (ICD) spectra and POM images of the GNRs capped with the (R)-enantiomer binaphthyl ligands between quartz substrates (crossed polarizers). (a) 0.5 wt.\% (R)-1-GNR in 5CB. (b) 0.5 wt.\% (R)-2-GNR in 5CB and (c) $0.5 \mathrm{wt} . \%(R)-3-G N R$ in 5CB. The positive signals of the ellipticity detected for each mixture confirm the induction of a right-handed $N^{*}$-LC phase. The black dashed line shows the averaged ICD spectrum from all sample rotation angles. The scale bar for all POM photomicrographs is $50 \mu \mathrm{m}$. 


\section{SECTION S3: EQUATIONS, DATA TABLE}

\section{Equations}

Number of gold atoms on the surface: Eq. S1: $N_{A u}=\frac{A}{A_{A u}}$

Number of ligands on the surface: Eq. S2: $\mathrm{N}_{\text {lig }}=\frac{A}{\text { Surface area of thiol }}$

$M_{W}$ of $A u$ atoms in GNRs $\left(g^{-1}\right.$ mol $\left.^{-1}\right)$ : Eq. S3: $M_{w}\left(A u\right.$ in NR) $=N_{A u} \times M_{w}(A u)$

$M_{W}$ of ligands in GNRs $\left(g_{\text {mol }}^{-1}\right)$ : $\quad$ Eq. S4: $M_{w}($ ligand in Au $-N R s)=N_{\text {lig }} \times M_{w}($ ligand $)$

Weight percentage of ligands in one GNR: Eq. S5: wt $\%$ (ligand in Au $-\mathrm{NRs}$ ) $=\frac{\mathrm{M}_{\mathrm{w}}(\text { ligand in NRs) }}{\mathrm{M}_{\mathrm{w}}(\mathrm{NRs})} \times 100 \%$

Correlation length between GNRs in induced N*-LC matrix (assuming well-dispersed GNRs):

Eq. S6: $\quad D=\sqrt[3]{\frac{2 \times M w \text { of } 5 C B \times N u m b e r \text { of } 5 C B \text { around } G N R S}{\text { Avagadro Number } \times \rho 5 C B}}-D_{G N R s}$.

\section{Data table}

Table S1. Dimensions, number of Au atoms $\left(N_{\mathrm{Au}}\right)$ as well as chiral ligands $\left(N_{\text {Ligand }}\right)$, and total molecular weight $\left(\mathrm{M}_{\mathrm{W}}\right)$ of the binaphthyl- and cholesterol-thiol-capped GNRs.

\begin{tabular}{llllll}
\hline GNR & Length $/ \mathbf{n m}$ & Width $/ \mathbf{n m}$ & $\boldsymbol{N}_{\text {Ligand }^{*}}$ & $\boldsymbol{N}_{\text {Au }}$ & $\mathbf{M}_{\mathrm{W}}{\text { of GNR } / \mathbf{~ g ~ m o l ~}^{-1}}^{-1}$ \\
\hline (S)-1- / (R)-1-GNR & $47.3 \pm 2.8$ & $11.1 \pm 1.6$ & 805 & 2674 & 640093 \\
\hline (S)-2- I (R)-2-GNR & $47.3 \pm 2.8$ & $11.1 \pm 1.6$ & 805 & 2674 & 684949 \\
(S)-3- / (R)-3-GNR & $47.3 \pm 2.8$ & $11.1 \pm 1.6$ & 805 & 2674 & 752221 \\
Si-(S)-GNR & $47.3 \pm 2.8$ & $11.1 \pm 1.6$ & 552 & 2674 & 685172 \\
Chol-GNR & $47.3 \pm 2.8$ & $11.1 \pm 1.6$ & 805 & 2674 & 710285 \\
\hline
\end{tabular}




\section{SECTION S4: DETAILS FOR QUANTIFICATION OF CHIRALITY}

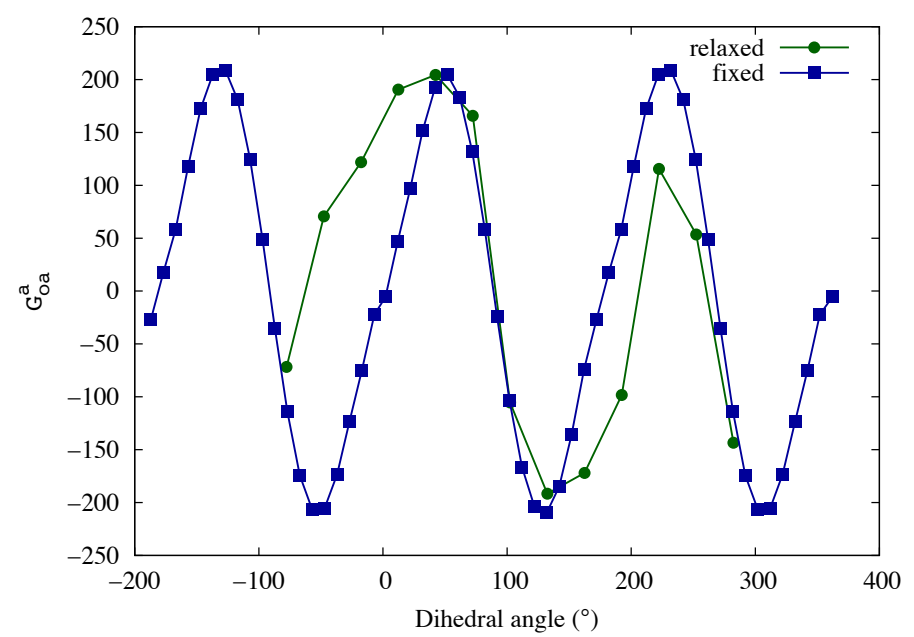

Figure S33. Chirality index, $G_{o a}^{a}$, profile for a rigid scan of the angle between the two naphthyl groups.

\section{SECTION S5: REFERENCES}

S1. Mori, T.; Sharma, A.; Hegmann, T. Significant Enhancement of the Chiral Correlation Length in Nematic Liquid Crystals by Gold Nanoparticle Surfaces Featuring Axially Chiral Binaphthyl Ligands. ACS Nano 2016, 10, 1552-1564.

S2. Sharma, A.; Mori, T.; Lee, H.-C.; Worden, M.; Bidwell, E.; Hegmann, T. Detecting, Visualizing, and Measuring Gold Nanoparticle Chirality Using Helical Pitch Measurements in Nematic Liquid Crystal Phases. ACS Nano 2014, 8 , 11966-11976.

S3. Nemati, A.; Shadpour, S.; Querciagrossa, L.; Li, L.; Mori, T.; Gao, M.; Zannoni, C.; Hegmann, T. Chirality Amplification by Desymmetrization of Chiral Ligand-Capped Nanoparticles to Nanorods Quantified in Soft Condensed Matter. Nat. Commun. 2018, 9, 3908.

S4. Ye, X.; Zheng, C.; Chen, J.; Gao, Y.; Murray, C. B. Using Binary Surfactant Mixtures to Simultaneously Improve the Dimensional Tunability and Monodispersity in the Seeded Growth of Gold Nanorods. Nano Lett. 2013, 13, 765-771. 